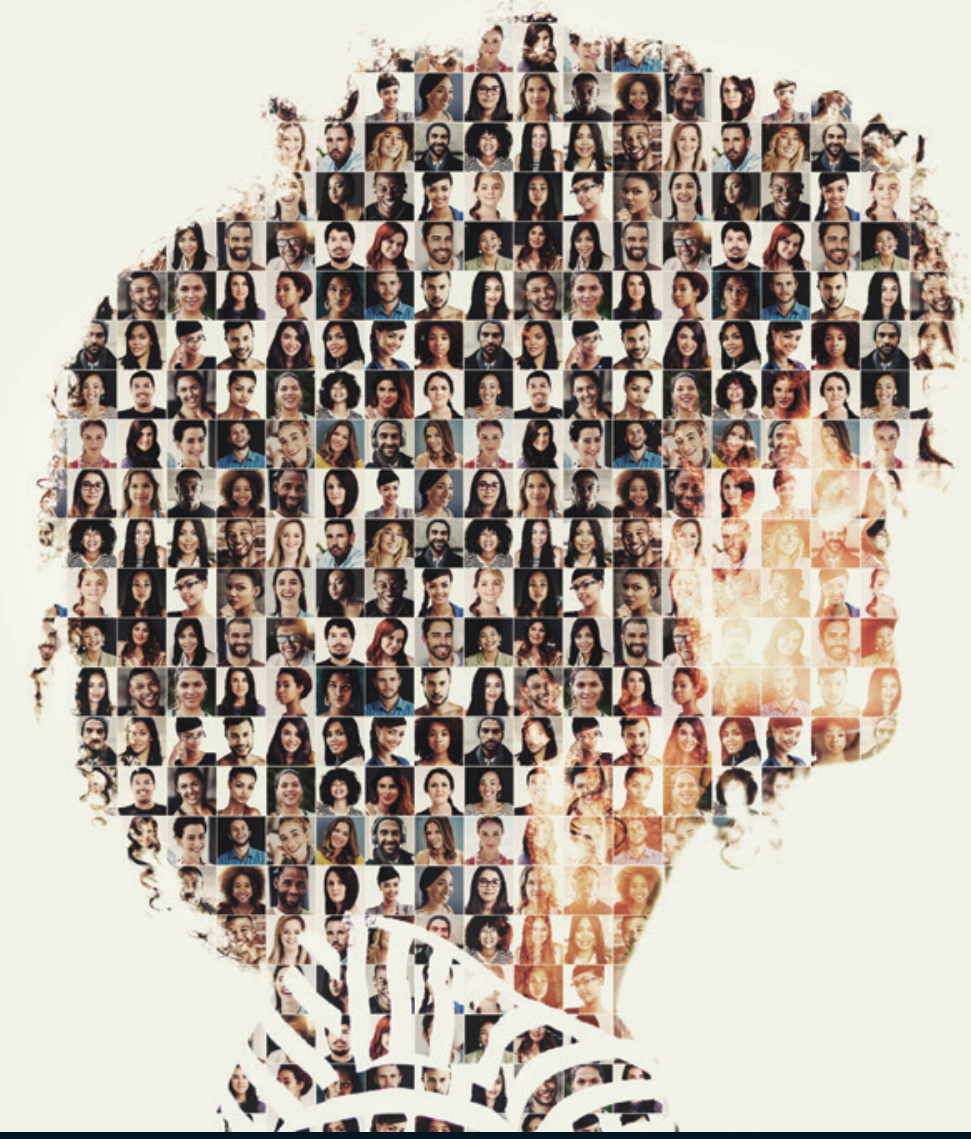

\title{
DELIVERING DIVERSITY.
}

Race and ethnicity in the management pipeline.

Prof Nic Beech, Prof Nelarine Cornelius, Dr Lisi Gordon, Prof Geraldine Healy, Prof Emmanuel Ogbonna, Dr Gurchathen Sanghera, Chidozie Umeh,

Dr James Wallace, Patrick Woodman 


\section{ACKNOWLEDGEMENTS}

This research was carried out by the Chartered Management Institute (CMI) and British Academy of Management (BAM). We have been greatly helped by a number of people who gave their time generously.

First, we would like to thank all those who gave their time to complete the questionnaire, shared ideas in discussion with us, gave us their time for interviews and took part in the case studies. We were struck by the enthusiasm of so many participants and their willingness to share insights and ideas to drive change on this agenda. We look forward to continuing to work with you to deliver diversity across UK businesses. In particular, we're grateful to those who contributed to the case studies:

- Jan Gooding, Global Inclusion Director, Aviva

- Simon Rodgers, Head of Diversity and Inclusion, Aviva

- Chuck Stephens, Head of Diversity and Inclusion, EMEA, Google

- Colin Clements, EA to Fiona Cannon, Group Director Responsible Business and Inclusion, Lloyds Banking Group

- Marjorie Strachan, Head of Inclusion, RBS

- Hannah Munro, Diversity, Inclusion and Early Careers Manager, Sainsbury's

- Rafael Campos Valdez, HR Business Partner - Diversity and Inclusion, Schroders

- Dan Perrett, Head of HR Business Partnering, Virgin Money

- Matt Elliot, People Director, Virgin Money

\section{The Research Advisory Board}

Secondly, we would like to thank the Research Advisory Board whose ideas, challenge and guidance were instrumental to the project, under the expert leadership of Pavita Cooper.

Pavita Cooper CCMI, Chair of the Research Advisory Board, Founder of More Difference

Béatrice Butsana-Sita, Managing Director, Capita Networking Solutions

Mary FitzPatrick, Diversity \& Inclusion Leader, GE Renewables

Parminder Kohli, General Manager Business Development, Marketing \& Operations, Shell

Anna Saunderson, formerly Head of Talent, Jupiter Fund Management plc

Jay Sheth, Head of Economics, Policy and Public Affairs, Virgin Money

Rachel Short, Director, Why Women Work

Chuck Stephens, Head of Diversity and Inclusion in EMEA, Google

Prosper Williams, Assistant Vice President - Digital Adoption and Engagement, Barclays

Petra Wilton, Director of Strategy, $\mathrm{CMI}$

\section{The research team}

The research was led by the British Academy of Management with a team from across several universities, led by Prof. Nic Beech and Prof. Nelarine Cornelius. CMI and BAM would like to thank the entire team for their crucial contributions.
Prof Nic Beech, Chair of BAM, Vice-Principal (Academic Planning and Performance), University of Dundee Prof Nelarine Cornelius, BAM Council (Research and Publications), School of Business and Management, Queen Mary University of London

Prof Udy Archibong, M.B.E., Director for the Centre for Inclusion and Diversity, University of Bradford

Dr Lisi Gordon, School of Management, University of St Andrews

Prof Geraldine Healy, School of Business and Management, Queen Mary University of London

Prof Emmanuel Ogbonna, Cardiff University Business School

Dr Gurchathen Sanghera, School of International Relations, University of St Andrews

Chidozie Umeh, School of Business and Management, Queen Mary University of London

Dr James Wallace, School of Management, University of Bradford

The contribution of the CMI team is also recognised:

Patrick Woodman, Head of Research and Advocacy

Ipek Noel, Research Manager

Dr Wahida Amin, Research Manager

Lysbeth Plas, YPL Research and formerly CMl's Research Manager 


\section{CONTENTS}

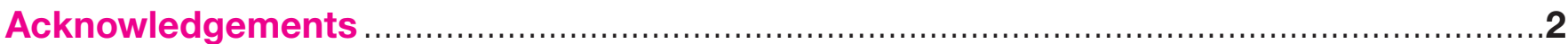

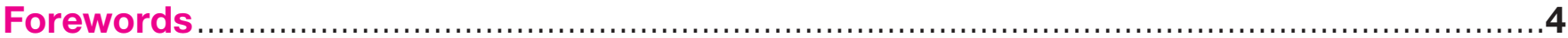

Pavita Cooper, Chair of the Research Advisory Board

Ann Francke CMI CEO and Prof Sir Cary Cooper CBE, BAM President

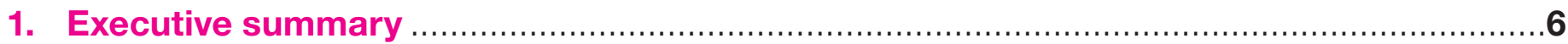

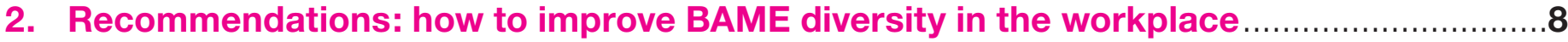

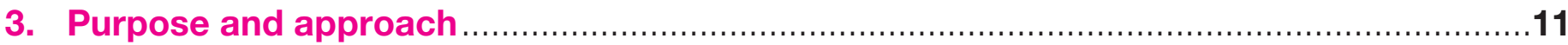

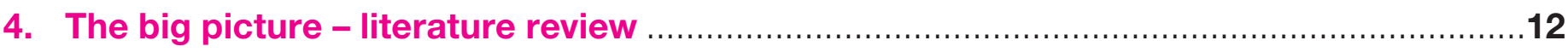

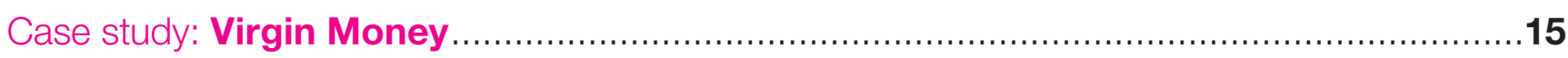

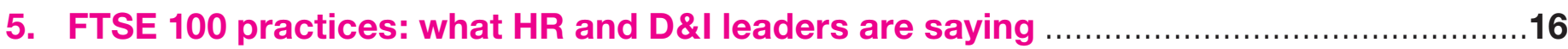

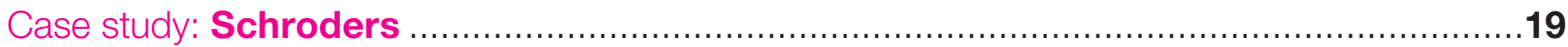

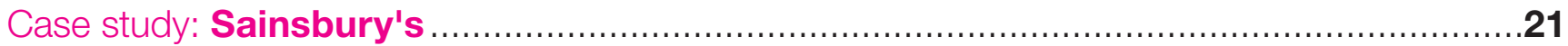

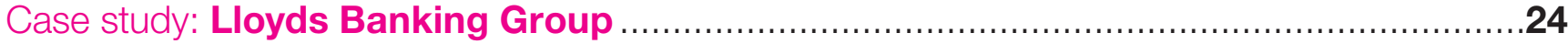

Case study: RBS

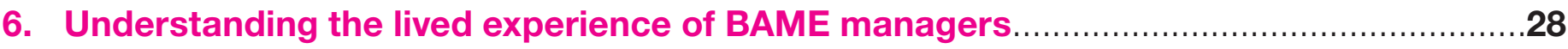

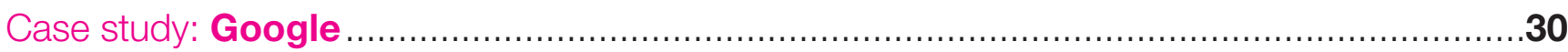

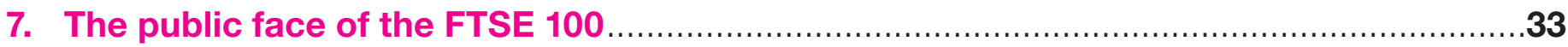

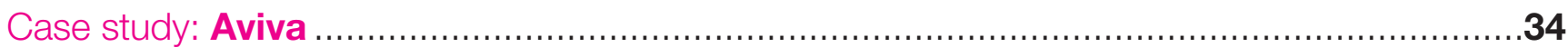

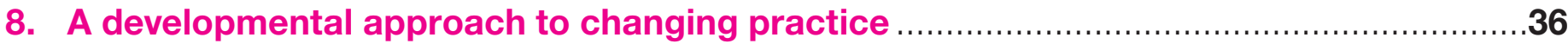

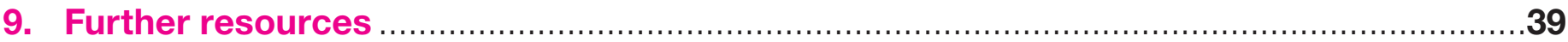

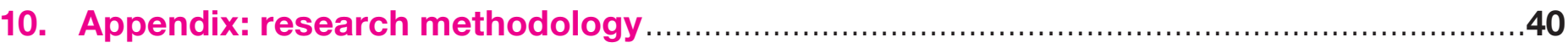

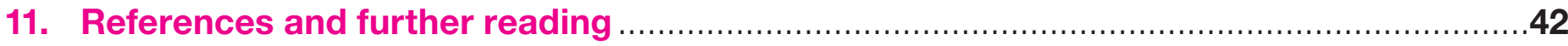




\section{FOREWORDS PAVITA COOPER}

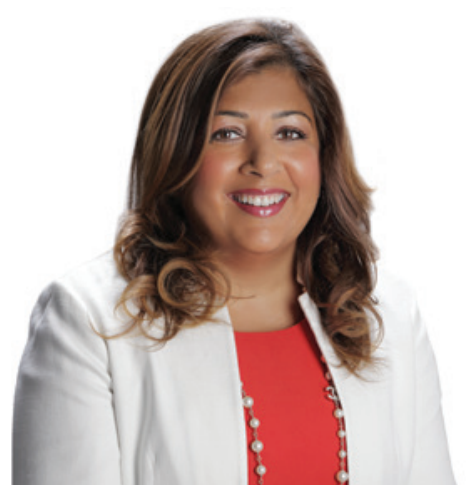

Pavita Cooper CCMI

Chair of the Delivering Diversity

Research Advisory Board,

Founder, More Difference

We've made significant progress with workplace diversity in recent years. Managers have heard and understood the business case: when you have ever-more diverse customers, you need diverse management and leadership to thrive.

Action to achieve diversity has been most visible on gender but when it comes to race and ethnicity, real progress has been much less tangible.

The recent McGregor-Smith and Parker reviews have outlined the scale of the challenge. Only 6\% of top management jobs are held by Black, Asian and minority ethnic (BAME) leaders, which just isn't good enough when BAME groups make up $12 \%$ of the working population. Parker called for at least one "leader of colour" on FTSE 100 boards by 2021. About time too: many boardrooms remain diversity-free zones.

But just as with gender, we won't make the progress that's needed if we only talk about the boardroom.
We have to go deeper into companies to understand why so few BAME managers reach the top, and how we can create a more diverse management pipeline at every level of business.

This research does just that. By talking to diversity leaders and to BAME managers themselves, it provides a rounded picture of the challenges.

It's resoundingly clear that we have to reboot the conversation about race and ethnicity. Business leaders need to set the tone and work with managers throughout the line to reshape business cultures. While this research focused on FTSE 100 companies, its findings are not relevant only to those businesses, important as they are to the health of UK plc. Its insights and recommendations for action point the way forward for managers in any organisation.

It's been my privilege to chair an excellent employer-led Research Advisory Board throughout this work, working with CMI and BAM, and I'm grateful to my Board colleagues for their brilliant input and support.

Moving forward, I'm delighted to be supporting the next phase of this work, as Chair of a new initiative, CMI Race. Our research made clear the need for a new focus on changing how managers engage with difference and diversity at every level of organisations. I look forward to working with managers from all sectors, of every background, and other partners in developing plans for CMI Race ahead of its full launch.

Business as usual won't cut it. The world is changing rapidly and leaders that don't respond will struggle to attract and retain the best talent in the future.

It's time to deliver on diversity.

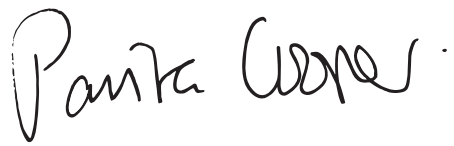




\section{ANN FRANCKE AND CARY COOPER}

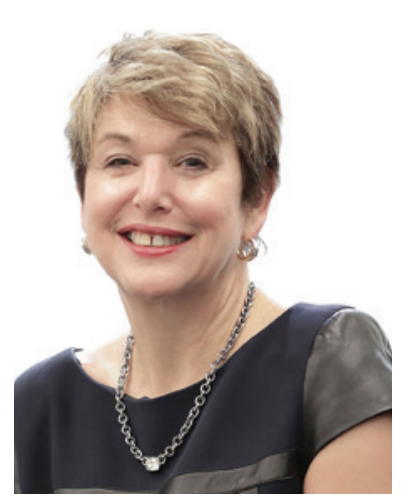

Ann Francke MBA CMgr CCMI FIC Chief Executive, CMI

For business, diversity is about talent, and how employers can attract, retain and make the most of people's abilities. Without doing a good job of growing talent, no business can prosper.

Discussions about talent have been given added urgency in the UK by the Brexit vote in 2016. While uncertainty persists about the outcome of negotiations with the EU, employers in all sectors have to face up to the prospect of reduced access to overseas talent. That makes it imperative that we think about how we can do better at making the most of everyone's abilities.

In particular, that means refocusing on how we develop world-class management and leadership skills, which are so fundamental to business productivity and performance - and which, the evidence shows, is one the of the biggest factors in the

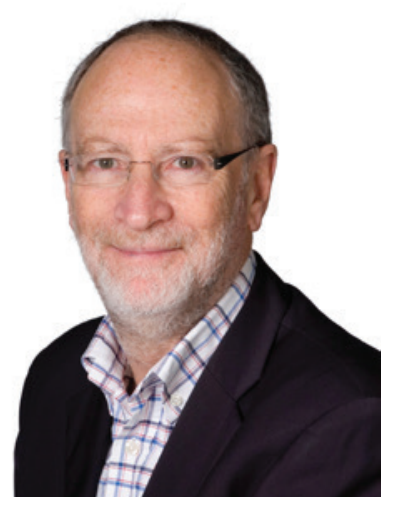

Prof. Sir Cary Cooper CBE

President, British Academy of Management

productivity gap between the UK and our competitors. As the professional body for management and leadership, and the learned society leading on research and higher education for management and business, $\mathrm{CMI}$ and BAM both have important roles to play.

The Brexit vote added impetus to our partnership. Our shared commitment to diversity at the heart of management and leadership made it a perfect combination and the research has been delivered in a superb spirit of collaboration and joint working. We are grateful to our teams and colleagues for their respective contributions and hard work over many months. The BAM research team drew together world-class scholars from a range of universities to develop an innovative methodology and work with a unique set of companies and diversity leaders. This style of working is exemplary in producing research that has the

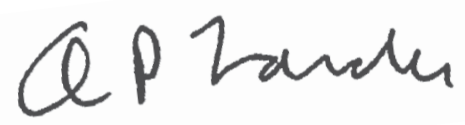

highest standards of rigour, combined with practical relevance and a focus on making a change in business and in society more broadly.

We're also grateful to Pavita Cooper and the Research Advisory Board for their immensely valuable contribution. They provided invaluable support throughout the project.

We would also like to thank all the leaders who engaged with the research, whether through roundtable discussions, through our survey, or through the personal and case study interviews. Their insights are at the heart of this report and its recommendations for action.

Delivering diversity demands action for individual managers and from employers alike, across every sector. We look forward to continuing to work together to achieve that change.

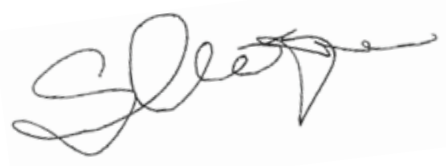




\section{EXECUTIVE SUMMARY}

\section{THE DIVERSITY OPPORTUNITY}

\section{Black, Asian and minority ethnic} (BAME) people are underrepresented in business and especially in management roles.

\section{It's time for change.}

\section{Drivers of change}

Around $12.5 \%$ of the UK population are BAME - yet they hold just $6 \%$ of top management positions. Closing this representation gap is an urgent challenge. The UK's BAME population is set to grow to $20 \%$ by 2030 and busineses are missing out on the talent they need.

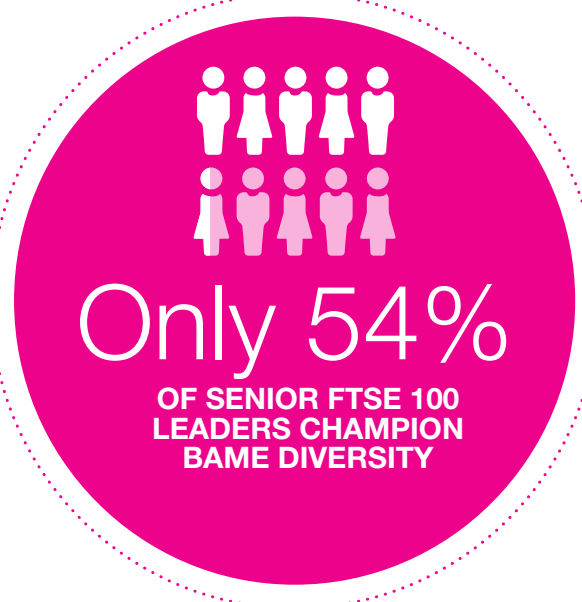

Global changes demand diversity too. FTSE 100 businesses already generate $75 \%$ of their income from outside the $\mathrm{UK},{ }^{2}$ and emerging markets are growing rapidly. More than ever, businesses need diversity of backgrounds, life experiences and viewpoints at every level of management.

The economic benefits are clear. Full representation of BAME individuals across the labour market would be worth £24bn a year to the UK economy.

The biggest business driver for diversity is improving performance, as $75 \%$ of $\mathrm{HR} /$ diversity leaders told us.
Despite that, not a single one of the diversity leaders we interviewed gave their company's current performance on BAME diversity top marks, a 'very good' rating. Only 54\% said that senior business leaders are championing BAME diversity.

That has to change. We need action now, to deliver diversity at every level of the management pipeline.
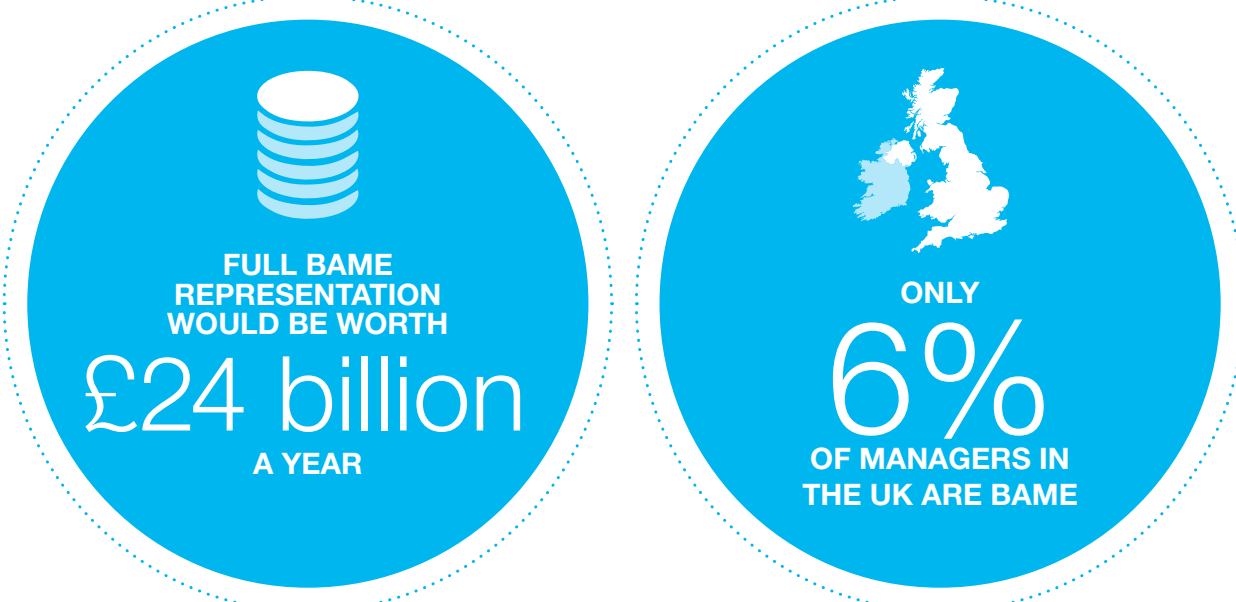


\section{KEY FINDINGS}

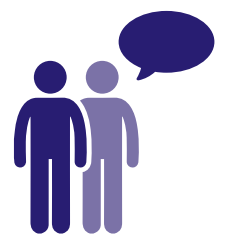

\section{LET'S TALK ABOUT RACE}

We need to end what one FTSE 100 leader described to us as "the silence around race and ethnicity." Many managers are uncomfortable discussing it and wary of causing offence. Only 54\% of $\mathrm{HR}$ /diversity managers see their business leaders championing BAME diversity. Leaders need to find their voice and show their commitment to diversity and to building inclusive business cultures.

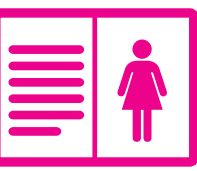

\section{LEARN FROM THE GENDER AGENDA}

Employers can transfer lessons from the progress made on gender diversity, among them the power of transparency to drive change. For now, BAME lags far behind. Only $21 \%$ of companies surveyed report publicly on BAME, compared to $71 \%$ on gender diversity. $42 \%$ even told us that the prioritisation of gender has become a barrier to progress on BAME: it has to be 'and', not 'or'.

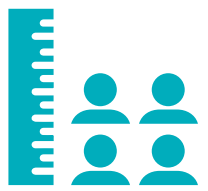

\section{FACE THE NUMBERS}

$83 \%$ of the HR/diversity leaders surveyed say they need better data to drive progress on race and ethnicity. Many report employee reluctance to share personal information, but data from across the employment cycle is vital to driving business improvements. Most powerfully, publicly setting and reporting on key diversity indicators is a major lever of accountability and change.

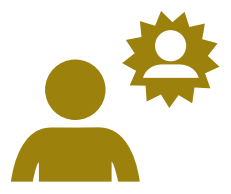

\section{IT AIN'T WHAT YOU KNOW - IT'S WHO KNOWS YOU}

Many BAME managers say their careers were significantly influenced by a senior executive who took a special interest. Managers at all levels need to make sure they support diversity through the emerging leaders they sponsor.

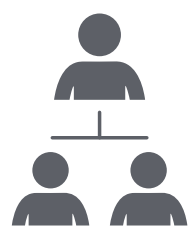

\section{WANTED: ROLE MODELS AND MENTORS AT EVERY LEVEL}

Role models show the company welcomes diversity. 'Next up' role models - drawn from all levels of a business, not just those at the very top - inspire confidence and ambition from those who follow them, showing that career progression is possible. Mentoring also needs to be encouraged at all levels; peer mentoring, mentoring circles and reverse mentoring offer powerful benefits.

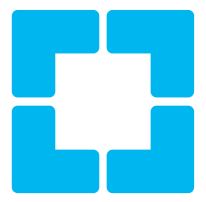

\section{FITTING IN?}

Many BAME managers question the perceived 'fit' for BAME employees in their businesses, pointing to norms that favour what one interviewee called "white middle class men from elite schools and universities." Some stressed the responsibility of BAME employees themselves to understand and navigate these differences. Internally, companies need to bridge this gap, tackling outdated cultures. Externally, they need to show a more diverse 'public face' in company websites and annual reports.

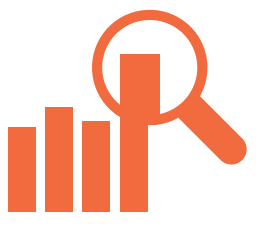

\section{EVIDENCE BASED DEVELOPMENT}

Companies should accelerate their progress by gathering evidence from outside the business, like good practice case studies and benchmarking data. This data can be used to identify opportunities for improvement and ways to develop key decision makers throughout the business - including, critically, line managers. 


\section{ACTION FOR LEADERS: IN SUMMARY}

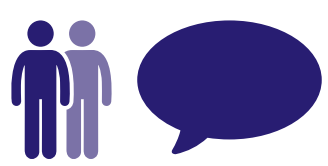

\section{BREAK THE SILENCE}

- Re-boot the conversation. Show commitment, make the business case and build employee buy-in to deliver diversity

- Support BAME networks to voice BAME employees' views

- Build line managers' capacity to deliver diversity. Make it OK to be curious and ask questions

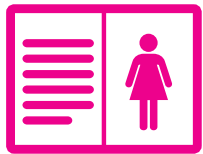

\section{CHANGE THE STORY}

- Generate momentum: make BAME your focus and define a plan for change

- Use the power of transparency. Publish your strategies, your targets and your progress

- Show inclusive leadership and call out bias

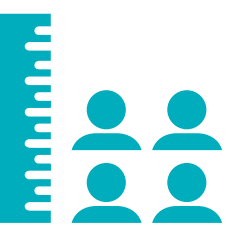

\section{MEASURE IT, MANAGE IT, REPORT IT}

- Measure BAME diversity throughout the talent pipeline, including representation at management levels

- Build employee trust and confidence for the use of personal data on ethnicity

- Establish pipeline indicators and use time-trend data to manage progress

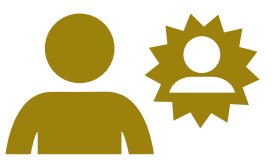

\section{TAP INTO THE POWER OF SPONSORSHIP}

- Create more opportunities for senior leaders to meet emerging BAME leaders and build diverse networks.

- Actively seek out diverse emerging leaders to sponsors and advocate for within the organisation

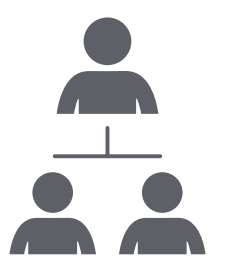

5. BUILD DIVERSITY THROUGH 'NEXT UP’ LEADERSHIP

- Identify and use 'next up' mentors and role models, not just remote senior leaders. Make mentoring the norm

- Use mentoring circles and reverse mentoring

- Share stories of diverse employees and showcase cultural differences

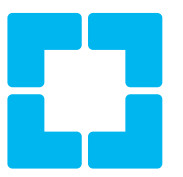

\section{BE INCLUSIVE AND ADAPTIVE}

- Make clear that the company values difference and diversity so no minority employee is left questioning their perceived 'fit' in the company

- Build adaptive cultures that respond to the differences people bring to work, rather than just asking others to fit in

- Prove to the external world that your organisation is diverse, remembering that your online presence is your public face

\section{BENCHMARK AND COLLABORATE}

- Benchmark with others in your sector

- Collaborate and share good practice to accelerate change

- Build diversity training into management and leadership development and make it a requirement for career progression 


\section{RECOMMENDATIONS: HOW TO IMPROVE BAME DIVERSITY IN THE WORKPLACE}

\section{SENIOR LEADERS}

1. 'Break the silence' and speak up with strong leadership on BAME diversity. Communicate a clear business case and build employee buy-in to organisational change. Senior leaders must show inclusive leadership by calling out any bias in their organisation, and encouraging all managers to do likewise.

2. Talk publicly and use all the company's communications channels to make clear the organisation's commitment to diversity. Can your people articulate the company's diversity culture when talking to clients?

3. Commit to collecting better data to enable change. Set aspirational targets to measure the company's progress. Be accountable for the results. And listen to staff views on how to achieve change and tackle barriers to progress.

4. Benchmark across your competition and collaborate to share good practice and accelerate change. Make diversity a company $\mathrm{KPI}$.

5. Make every manager and leader accountable and identify champions across senior and middle management levels so it has ownership beyond the CEO. Embed diversity as a factor in business decisions.
6. Seek out talented BAME employees to sponsor and mentor. Get your senior managers and direct reports to do the same.

7. Implement the 'pathway to development' for BAME diversity described in Chapter 8 below.

\section{HR/D\&I LEADERS}

1. Measure and monitor diversity in HR processes and set targets for progress, from recruitment right through the talent cycle.

2. Make diversity real by using case studies and stories to engage colleagues across the company, BAME and non-BAME alike. Celebrate cultural events to promote a culture of inclusivity.

3. Develop managers' capability to talk about race. Integrate diversity training into management development, at senior levels and throughout the pipeline, to give managers the confidence to talk about race and diversity.

4. Ensure all high potential BAME employees are actively mentored or sponsored to support progression.

5. Work towards measuring and addressing any BAME pay gap, building on the gender pay gap rules already in place for large business.
6. Engage with employees on why it is vital to disclose background information to HR. Explain why data is so important to driving change and earn trust in how it is used.

\section{LINE MANAGERS}

1. Celebrate cultural diversity in your team. Be curious and ask questions about cultural differences.

2. Don't be afraid to ask for help on how to break the silence on race and ethnicity. Take the lead with your professional development and seek out training, for instance, in unconscious bias or inclusive leadership.

3. Focus on developing others. Act as a next-level role model for inclusive leadership and support others' development through mentoring.

4. Signal your availability to talk about difference, and make it possible for all employees to do the same. Actively call out biased behavior with a focus on learning and development, and encourage your team to do so. 


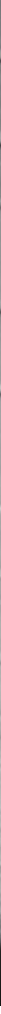

\section{BAME COMMUNITIES}

1. Help break the silence, including colleagues who fear making mistakes to discuss difference. Engage with business initiatives to support and discuss diversity. Share your background information with HR when they collect ethnicity data and encourage others to do the same.

2. Put yourself forward. Differences in organisational norms and expectations can prevent BAME employees from asking for support or guidance. Ask for more, from line managers, mentors and sponsors, and from the business.

3. Seek formal opportunities to develop new skills. Network with, and learn from, peers.

4. Challenge outdated cultural norms in your company. Nobody has to accept a company's culture just the way they find it. Talk about differences and question the status quo.

\section{POLICY-MAKERS}

1. Encourage transparency through reporting on the BAME pay and progression gap. Work closely with the management community to shape policy, champion industry leaders, and share emerging good practice on this complex challenge.

2. Champion progressive employers and encourage others. Work with business to develop aspirational targets for BAME representation in all levels of management, not just the boardroom, and for action on pay.

3. Address inequalities in educational access and attainment for BAME students. Businesses' ability to shape the management pipeline is influenced by the intake: government can help ensure a focus on growing employability skills among all students, including BAME groups, and should look, in particular, at the skills needed by growth sectors. 


\section{PURPOSE AND APPROACH}

\section{This research aimed to:}

- understand the presence and representation of Black, Asian and minority ethnic (BAME) managers and leaders in FTSE 100 companies

- analyse problems and barriers to progression of BAME managers

- uncover company and individual actions which are helpful in enabling progression

- make recommendations to accelerate inclusivity and enable UK organisations to benefit from a greater proportion of BAME managers and leaders.

\section{The approach taken included:}

- a review of current literature, research reports and policy documents relevant to BAME diversity in the FTSE 100

- identification of key themes and practices through a workshop and roundtable discussion including 13 companies, hosted by Google

- follow up data gathered with 26 interviews with pairs of BAME and non-BAME managers in equivalent positions across 12 FTSE 100 companies $^{4}$
- analysis of the public face, policies and performance of all FTSE 100 companies through a web-based evaluation

- an online survey of $24 \mathrm{HR}$ or Diversity and Inclusion (D\&I) leads, to build a picture of diversity practice regarding BAME representation and practices in the FTSE 100

- case studies of seven companies (five in the FTSE 100, one exemplar from the FTSE 250, and one exemplar outside the FTSE 250).

As this report shows, many managers are nervous of talking about race and ethnicity, wary of causing offence by using words that some find inappropriate. We recognise that there is an ongoing debate about the best language to use. The Parker Review refers to 'people of colour', a term often used in the US. BME - black and minority ethnic - is still widely used. Others have suggested 'visible minorities.'

We decided to use BAME - Black, Asian and minority ethnic - and non-BAME, terms that are widely used and understood across business and academia alike. Even these have limits though. For instance, one global business we interviewed said they avoid using BAME, because it does not translate to territories where black or Asian people are in the majority. It could also be interpreted as implying that BAME people are a homogeneous group, which is clearly not the case. We have written in this report of BAME groups or communities in the plural: businesses also need to avoid thinking in overly simplistic terms. A similar point could be made about the diversity of non-BAME groups.

Different businesses may settle on different terms. Whatever the language, we emphasise that the important thing is for businesses to have the conversation in the first place and to take action that delivers change. As one leader told us: Better to apologise for something said with the best of intentions, than to stay silent and perpetuate the real issues around diversity at work. 


\section{THE BIG PICTURE - LITERATURE REVIEW}

To set the context for our research, we reviewed the latest literature from business, policy and academia. This summary synthesises key insights about the situation of BAME leaders and managers in the UK, and what's known about the FTSE 100 specifically.

\subsection{The management population and the working population as a whole}

Diversity in management is an increasingly high-profile issue for business, with recent reports such as the Parker Review on the ethnic diversity of UK Boards (2016), led by Anglo-American Plc Chairman Sir John Parker, and the review by the former Mitie CEO, Baroness McGregor-Smith, on Race in the Workplace (2017).

These reports make clear that business imperatives are changing. Consumers are increasingly international and diverse in race and ethnicity, globally and in the UK. Between 2015 and 2050 , it is projected that one half of the world's population growth will be concentrated in nine countries, five of which are in Africa and three in Asia. ${ }^{5}$ Currently, the FTSE 100 derives more than $75 \%$ of its sales from outside the UK. Future commercial success is therefore likely to require more diverse business leadership.
In the UK, some 14\% of the population are currently from BAME groups. By 2030, this proportion is expected to rise to $20 \%$, reaching over $30 \%$ by 2051. ${ }^{6}$ Employment rates among BAME groups of working age are lower overall, at $62.8 \%$ compared to $75.6 \%$ for individuals identifying as white. Among Pakistani and Bangladeshi groups the employment rate drops to 54.9\%.?

There is also a pronounced representation gap in management and leadership roles. In 2007, only $6.8 \%$ of the BAME working population were described as being in management positions. ${ }^{8}$ What's more, this gap appears to have widened between 2007 and 2012. ${ }^{9}$

In total, analysis by the UK's Department for Business, Energy and Industrial Strategy shows that the potential benefit to the UK economy from full representation of BAME individuals across the labour market, through improved participation and progression, is estimated to be £24 billion a year (1.3 $\%$ of GDP). ${ }^{10}$

In short, whilst there are changes in economically active populations in production and consumption both in the UK and around the world, these changes are yet to be reflected in the general UK working population or senior leadership. If there is no change, the gap between the population and business leadership will widen, raising both ethical questions of fairness in selection and inclusion, ${ }^{11}$ and questions about business performance in a diverse world.

\subsection{BAME diversity in higher education}

Increasingly, the management and leadership population is drawn from graduates, so the diversity of the student population is important to the future management pipeline. In 2007, BAME students made up $17 \%$ of UK undergraduates, which would suggest an increase in the BAME working population in future. However, as these BAME graduates are in their early years in the job market, there is no evidence yet of any increase in those reaching management positions. ${ }^{12}$

Analysis has shown that elite universities, such as the Russell Group, do not have proportionate BAME groups. ${ }^{13}$ BAME students tend to study in cities with a high BAME population, clustering around London, Birmingham and Bradford. When it came to subject choice, BAME students were found to favour entrepreneurial subjects. However, differences were found in employability post-university, where a smaller proportion of BAME graduates compared to non-BAME graduates found graduate level jobs. In 2012, only 10\% of workers on the first rung of the promotional ladder were from BAME groups. ${ }^{14}$ 


\subsection{An issue with the management pipeline?}

A previous study by CMI of BAME and non-BAME managers showed that higher proportions of black and Asian managers indicated that they would like to become a CEO, a board director or a non-executive director. However, the existence of an 'old boys' network', a lack of career guidance, and discrimination were all identified as barriers to progression. ${ }^{15}$

Unconscious bias has been an increasing area of focus for businesses and researchers. Analyses of trends in management and leadership recruitment suggest unconscious bias may play a role during all stages of the process, affecting BAME candidates. ${ }^{16}$ Other research suggests that a dominant 'white, male' discourse in organisational culture affects the 'acceptable criteria' used in recruitment and promotion. ${ }^{17}$ BAME candidates may not be regarded as meeting these 'traditional' criteria and are less likely to be seen to have the potential to 'fit' with cultural perceptions of a 'good leader'.18 Even the provision of feedback to candidates has been found to be more extensive for non-BAME than BAME people. ${ }^{19}$

Reinforcing the notion of a perpetuating white, male discourse, an interview study of 130 BAME and non-BAME women found that $90 \%$ of BAME women felt they had to leave their culture behind in order to progress in their organisation. ${ }^{20}$ This was despite perceiving that their cultural identity impacted on their own approach to leadership. Many women, in particular from the Bangladeshi and Pakistani ethnic groups, believed they were discriminated against. This finding is reflected elsewhere, where appearance, religious belief and traditions were repeatedly questioned and there was a perceived obligation to participate in out-of-work activities that made them feel uncomfortable. ${ }^{21}$ Additionally, while half of BAME participants felt that their organisation was a place for progression, many felt that they were under-utilised (30\%) or overlooked (18\%). ${ }^{22}$
Further research on intersectionality informs us that BAME professional women often fare less well than BAME professional men who, in turn, fare less well than non-BAME professional men. ${ }^{23}$ Hence, when collecting data companies will need intersectional data by gender and race/ethnicity and other protected characteristics, such as disability, age and sexual orientation, in order to properly understand the nature of dynamics in the pipeline.

Differences in workplace culture may also affect satisfaction at work. One survey of 24,457 workers found that a higher proportion of BAME employees (65\%) said they enjoyed working for their organisation than their white colleagues (61\%). However, a high proportion of Bangladeshi (34\%), black Caribbean (29\%) and black African (24\%) employees said they were dissatisfied with their career progression. ${ }^{24}$

In this survey, BAME employees also reported witnessing or experiencing bullying/harassment from managers (reported by $28 \%$ of BAME employees), from colleagues (32\%) or clients/customers (17\%). ${ }^{28}$ In the wider literature, bullying and harassment are reported to be enacted disproportionately on BAME workers. ${ }^{25}$

When it comes to enabling progression, there is some evidence about what works. Mentoring is one area that has been identified as a crucial positive factor in supporting BAME career progression. ${ }^{26}$ In one interview study in 2012, more BAME employees had mentors, sponsors or role models. A higher proportion of BAME employees that did not have a mentor would have liked one than their white colleagues. Similarly, a higher proportion of BAME workers (40\%) were interested in fast-track management programmes compared to their white colleagues (18\%), but only $8 \%$ of BAME employees had gained places on such programmes. ${ }^{27}$
Mentoring is one area that has been identified as a crucial positive factor in supporting BAME career progression. 


\subsection{Focusing on the FTSE 100}

There is little research relating to the FTSE 100 specifically. A snapshot of ethno-cultural diversity in the top rungs of these companies shows that BAME groups are underrepresented at top levels. ${ }^{28}$ Table 1 opposite depicts the numbers of BAME leaders in the top levels of these companies in 2014 and 2015. While some changes may reflect companies moving in and out of the FTSE 100 as well as changes within companies, the overall message is clear. Fifty three FTSE 100 companies had no directors from BAME groups and just seven companies accounted for over $40 \%$ of BAME representation at director level - five of these seven having previously been headquartered outside the UK. ${ }^{29}$

Health, banking and finance rated relatively highly for diversity in leadership roles, while utilities, engineering and construction and property were least diverse in their top leadership.

\subsection{Conclusion: implications from the literature and the future of UK business}

The literature shows that while the BAME working population has increased in recent years, this is not reflected in the diversity at senior management levels. This lack of ethno-cultural diversity is apparent in the FTSE 100. Issues with the pipeline for management and leadership have been identified including organisational culture issues, a lack of effective mentoring and monitoring, culture-specific construction of selection criteria, unconscious bias, and bullying and harassment, which can deter people from applying.

\begin{tabular}{|l|c|c|}
\hline FTSE $\mathbf{1 0 0}$ companies & $\mathbf{2 0 1 4}$ & $\mathbf{2 0 1 5}$ \\
\hline Number of Chairs who are BAME & 2 & 3 \\
\hline Number of CEO who are BAME & 6 & 4 \\
\hline Number of CFO who are BAME & 3 & 4 \\
\hline$\%$ Non-executive directors who are BAME & 5.8 & 6.8 \\
\hline \% Executive directors who are BAME & 5.2 & 4 \\
\hline \% Operating board members who are BAME & 6.5 & 7.4 \\
\hline
\end{tabular}

Table 1: BAME group leadership and management representation in FTSE 100 (adapted from Green Park Leadership 10,000, 2014 and 2015).

A lack of inclusion is not only a problem for business. In the wake of the EU Referendum result, the Home Office noted a "sharp increase" in racial abuse and harassment. ${ }^{30}$ In this context, business has an even more important role in improving inclusivity and diversity. ${ }^{31}$

However, detailed questions of what business should do, and how to do it, remain under-researched. There are many helpful suggestions and recommendations, but there is relatively little multi-method, in-depth research that seeks to go beyond the 'what' question into the 'how' and 'why' questions of changing practice: something this report seeks to address.
2014 - \% BAME

\begin{tabular}{|c|c|c|}
\hline \multicolumn{3}{|l|}{ Top 20 Roles } \\
\hline Top 3 sectors & $\begin{array}{l}\text { Natural resources (11.2\%) } \\
\text { Industrials (9.5\%) } \\
\text { Health (9.0\%) }\end{array}$ & $\begin{array}{l}\text { Health }(15.9 \%) \\
\text { Natural resources (11.7\%) } \\
\text { Technology }(9.1 \%)\end{array}$ \\
\hline Bottom 3 sectors & $\begin{array}{l}\text { Engineering (2.0\%) } \\
\text { Construction and } \\
\text { Property (1.6\%) } \\
\text { Utilities (0\%) }\end{array}$ & $\begin{array}{l}\text { Construction and } \\
\text { Property (2.2\%) } \\
\text { Utilities (0\%) } \\
\text { Transport (0\%) }\end{array}$ \\
\hline \multicolumn{3}{|l|}{ Top 100 Roles } \\
\hline Top 3 sectors & $\begin{array}{l}\text { Natural resources (10.4\%) } \\
\text { Industrials (9.5\%) } \\
\text { Health (8.0\%) }\end{array}$ & $\begin{array}{l}\text { Health }(10.3 \%) \\
\text { Banking and Finance (8.1\%) } \\
\text { Consumer }(6.4 \%)\end{array}$ \\
\hline Bottom 3 sectors & $\begin{array}{l}\text { Construction and } \\
\text { Property }(1.6 \%) \\
\text { Engineering (1.0\%) } \\
\text { Utilities (0.0\%) }\end{array}$ & $\begin{array}{l}\text { Construction and } \\
\text { Property }(3.1 \%) \\
\text { Engineering (2.6\%) } \\
\text { Utilities (1.8\%) }\end{array}$ \\
\hline
\end{tabular}

Table 2: BAME group representation in the FTSE 100 by sector (adapted from Green Park Leadership 10,000, 2014 and 2015). 
Virgin Money's People Director, Matt Elliott, and Head of HR Business Partners, Dan Perrett, describe a range of exciting initiatives and innovations relating to BAME diversity and inclusion practices. As a FTSE 250 company, Virgin Money currently employs 3,000 people in the UK. Following the acquisition of Northern Rock in 2011, the company expanded tenfold. This rapid change in employee profile has pushed the diversity and inclusion agenda to the fore in the last three years. Their BAME diversity and inclusion work is ongoing and will continue to take priority for ongoing development over the coming years. Among many examples, a few of their innovative practices are described here.

Overall company ethos and approach to BAME Diversity and Inclusion Virgin Money's central purpose of Everyone's Better Off (EBO), is seen to be all-consuming and part of all employees' day-to-day work. This ethos is about fairness, transparency and encompasses diversity and inclusion. The purpose around EBO is to be welcoming and equally engaging to all. This ethos applies both to how Virgin Money aims to serve customers and how company employees are treated. To facilitate EBO, an ExCo member has responsibility for each dimension of diversity, including BAME. The company has an action plan for BAME diversity and inclusion from which progress is reported at Exco every month.

"EBO for colleagues [comes] down to being welcoming to all and we want it to be equally engaging for the people who are here - where people can simply be themselves at work."

Tracking company BAME diversity As early adopters of the recommendations from the Parker Review, Virgin Money have implemented BAME diversity measures in a range of ways. First, they are tracking recruitment data; second, an annual engagement survey $(94 \%$ completion rate) has for the last four years included a diversity and inclusion element; third, the company has asked employees to complete an "About me" survey which is in its second year. This is helping complete the employee data profile in the core HR system. These measures allow the company not only to track trends, but explore how minority groups feel about managers and the opportunities they have for access to leadership pipelines. The data is finegrained enough to track diversity trends at a local level. For example, population diversity of the North East of England is different to that of London. This means that diversity targets can be set to reflect the local population. Additionally, these measures allow the company to track the effectiveness of their diversity and inclusion initiatives and listen to employees to determine how to improve.

"We have adopted the Parker Review now. The report says we have to 2024 as a FTSE 250 company to be compliant... it's now live, we'll comply with the recommendations before then... We've got to create a talent pipeline to make sure that happens."

\section{Affinity Group}

Over the past year, Virgin Money has launched an Affinity Group, which is employee-led and focused on building diversity. While at an early stage of development, the Affinity Group has split into specific networks (including BAME) and they are developing actions plans for what they want to do and support. Examples of work they propose to do include: identifying and training BAME role models in the company; the rollout of unconscious bias training company-wide in 2017; and connecting with the local business community on diversity issues.

"Through the Affinity Group we effectively go to all our BAME people in our organisation [and ask] 'so how do we put you in a place where you can be a role model for the company?... It doesn't matter what your seniority is, we want you to be someone who can talk confidently about this company to [BAME] people... in return we will equip you to be able to do that."'

A partnership approach to facilitate BAME talent pipelines

Virgin Money emphasises the importance of partnership working to create BAME talent pipelines. As a founding member of EMpower and with their continued support of the British Black Business Awards (BBBA), this is prioritised through education, mentorship and the identification of BAME role models within the company and through these partnerships.

"We want to make sure the [Affinity Group's] action plans are dedicated and achieving what we want...appreciating that, although there might be commonality between gender and ethnicity in terms of needing mentoring, there might be different ways we will approach mentoring... From an ethnicity point of view, we may not have the right mentors in-house, so we will work with EMpower or the BBBA to say 'can you get someone in your existing organisation partners to help mentor?'”

Storytelling to facilitate diversity and inclusion

Virgin Money also recognise that sometimes the little things can bring about cultural change. A bottom-up development in Virgin Money has been the use of storytelling. Employees are encouraged to write a memo about an experience (for example, what it is like to be a Muslim woman in the company) and place it on the company intranet. These stories are widely read by company employees. Authors of these stories have reported a huge influx of personal support and these stories have led to companywide learning about diversity.

"She simply wrote a memo [of her personal experience of being a Muslim woman] and we put it on our intranet... We were taken aback when we saw that over 2,000 of the 3,000 people in our company individually read it... so we started to get people coming forward and saying, 'l'd quite like to share my story'... People are writing about their own faiths... these stories get read in the company... so some of the little things really bring about cultural change." 


\section{FTSE 100 PRACTICES: WHAT HR AND D\&I LEADERS ARE SAYING}

\section{What are companies doing to address the under- representation of BAME groups in the management pipeline? We surveyed HR and Diversity/ Inclusion leaders about current activity - and found a widespread view that business needs to do much more to drive change.}

Our survey of HR and D\&I leaders across the FTSE 100 was designed to understand the human resource management practices being used to promote diversity of staff, and to identify the actions undertaken to support recruitment and progression of BAME employees.

Findings are presented in three sections: company performance on, and attitudes towards, diversity
(Section 5.1), good practice approaches (Section 5.2) and resourcing (Section 5.3).

Respondents were also asked what would be the one change that they would identify that would most improve the career progression of BAME managers in their company. These responses have been highlighted throughout this Chapter.

Twenty four companies responded to the survey, enabling insight into the diversity practices of nearly a quarter of FTSE 100 companies. While we are careful about generalising from the results, they do provide valuable insights into leading companies' approach to the BAME pipeline and associated HR and diversity practices. $^{32}$
5.1 Company performance on and attitudes towards diversity Respondents rated their organisations' performance in creating a diverse management pipeline, both in terms of race and ethnicity and on dimensions such as gender, sexual orientation, age and disability. Just $17 \%$ rated current performance on race as good; 46\% rated it as average; and 38\% rated performance as fairly poor or very poor (see Figure 1). None rated their company's record as very good.

One respondent stated: "The lack of BAME people in my company makes me feel ashamed. It is inexplicable unless you accept there must be discrimination in our culture."

This poor rating of BAME diversity performance is in contrast to gender,

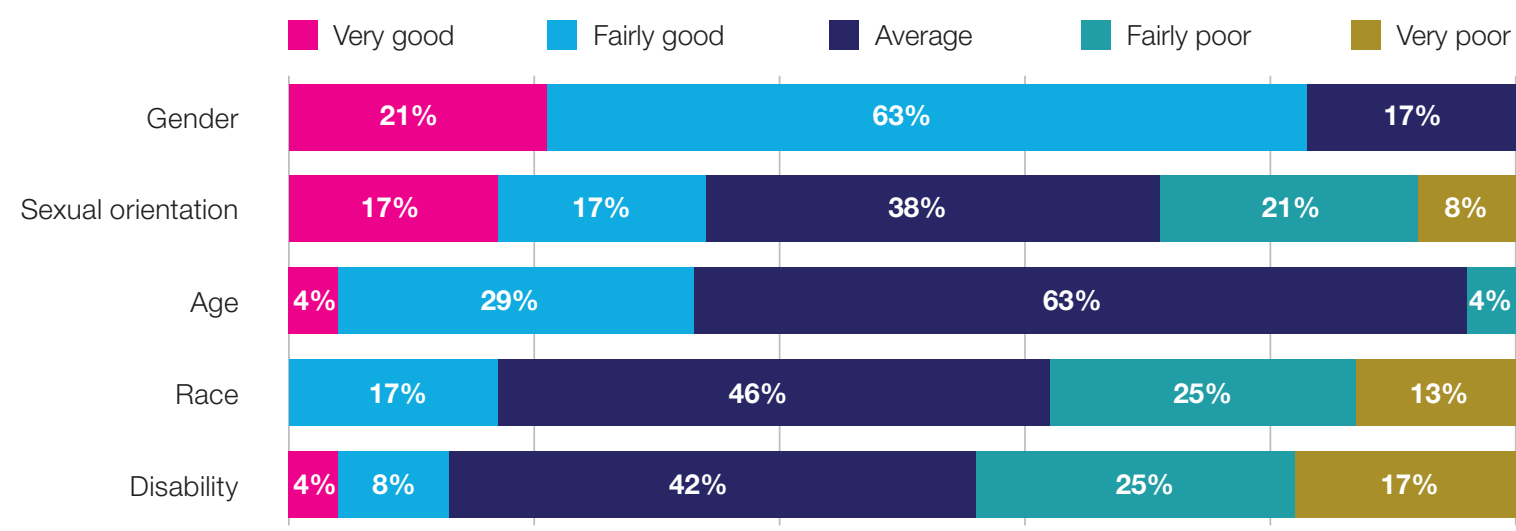

Figure 1: Rating company performance in creating a diverse management pipeline ${ }^{33}$ 
A person's race or ethnicity has no impact on their career prgression in my company

My company is taking active steps to improve race and ethnic diversity throughout the management pipeline

Senior leaders actively champion race and ethnic diversity in the management pipeline

where $84 \%$ reported that their organisations' performance was fairly or very good.

These results are fully supported by our discussions with HR and D\&l leaders throughout this project. Many told us that the "gender agenda" was at a more advanced stage of action, with many feeling that they were just beginning to work on BAME diversity - which may prove more complex. For one such company, see our Virgin Money case study, page 15.

\section{Data on the management pipeline} $83 \%$ of respondents reported their company needed better quality data to improve race and ethnic diversity. Data collection on BAME is an on-going challenge for FTSE 100 companies, not least to be able to map the current representation of BAME employees in the management pipeline. One respondent explained: "We started voluntarily collecting diversity data a couple of years ago and have had a low response. So although we hold data, we don't have sufficient to be able to split by management level so these are estimates of the proportions at those levels."

Based on what data they do have, respondents reported that BAME representation in their companies was particularly low at senior levels (see Figure 3). 54\% reported they
Agree Neither agree nor disagree $\square$ Disagree

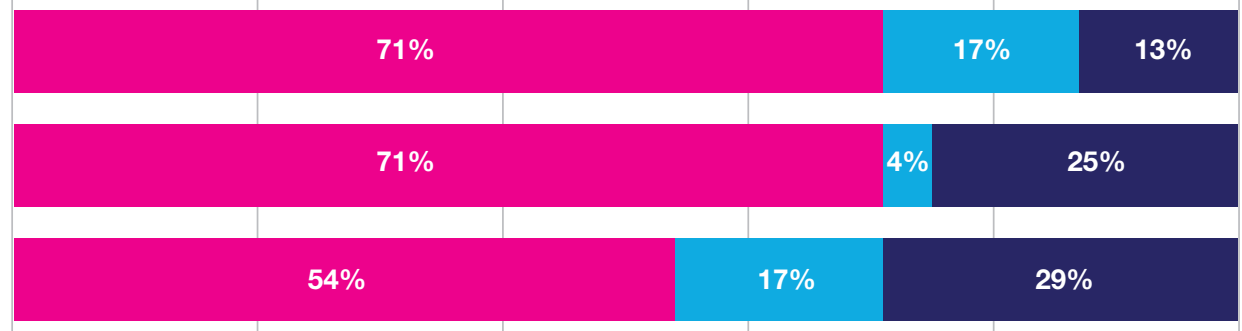

Figure 2: Attitudes towards company performance on BAME diversity.

have fewer than five per cent BAME at senior management level, and $83 \%$ report they have this low level at board level, indicating another area for improvement.

One respondent noted: "[We are] below the average for the UK working population and [diversity] declines as the seniority increases. There is definitely a lack of proportionate BAME representation from middle management upwards. This is visible across all business areas in our company."

Geography and the location of the company's workforce is also a relevant factor for some: "We don't have representation even in locations (like London) where you might expect a higher proportion. It's shockingly bad. And [that] does seem to be exacerbated by the fact that [our sector] is not necessarily a career of choice at the best of times. Our reputation as an industry is poor."

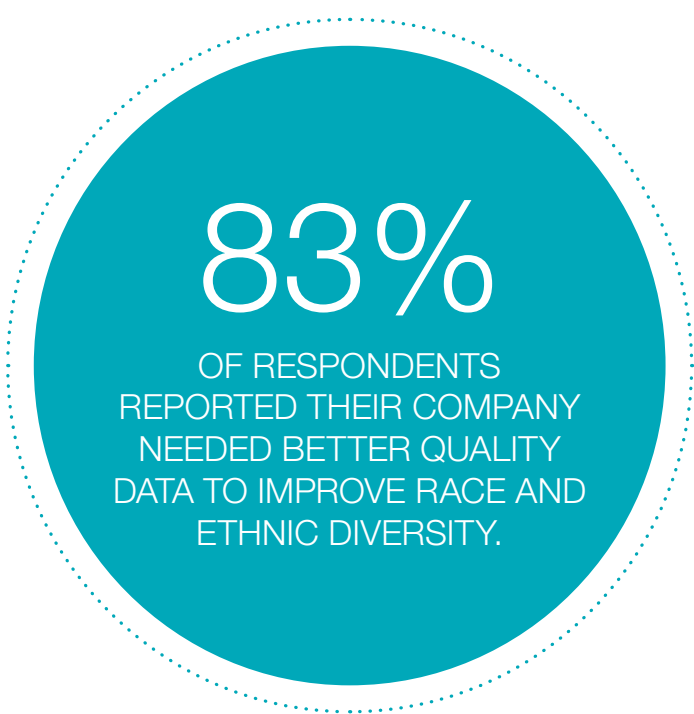




$\begin{array}{lllll}\text { Less } & \text { Between } & \text { Between } & \text { More } & \text { Don't know } \\ \text { than } 5 \% & 5 \% \text { and 10\% } & 10 \% \text { and 20\% } & \text { than 20\% } & \text { / not sure }\end{array}$

$100 \%$

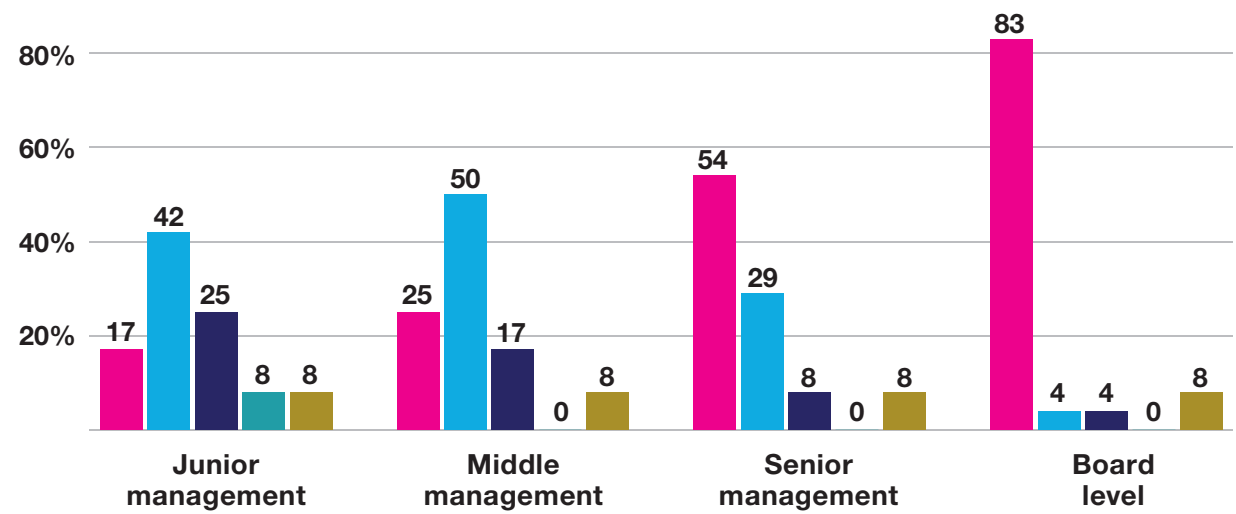

Figure 3: Percentage of BAME employees across the management pipeline in the UK (based on data available or estimates)

\section{Monitoring and reporting on performance}

Reflecting the challenges of collecting good quality data, we found a declining scale of action with respect to how BAME data is used (see Table 3). While $79 \%$ collect and hold some employee data - albeit perhaps limited or poor quality data - only $54 \%$ then monitor and track diversity. Only $21 \%$ report publicly on race and ethnicity and set progression and representation targets. In contrast 75\% set progression/representation targets for gender. This result is reflected in the case studies in which companies stated that targets were difficult to set before appropriate data were collected.

Engaging staff by setting targets for progression and representation at different levels in an organisation is an essential requirement for organisations to take BAME equality seriously. Encouragingly, almost half (47\%) of those who do not currently have targets stated that they planned to set progression targets in the next 12 months. For some this was their 'One Change' (see Box A).

Targets were often aspirational, for example: "We have put in place aspirational targets which ensure that we have representation on development programmes which are in line with UK averages. Our... programmes are essential for those moving between grades. Cohorts should not go ahead if they are not representative, making managers look for talent harder. We have also hosted BAME-only colleague development events."

Another respondent stated: "We aspire to have $18 \%$ BAME representation in our... manager population with a staging target of $14 \%$ by $2018 . .$. and $10 \%$ BAME representation in our senior manager and departmental director population by 2020."

\begin{tabular}{|c|c|c|c|c|}
\hline & $\begin{array}{c}\text { Collects / } \\
\text { holds employee } \\
\text { data (\%) }\end{array}$ & $\begin{array}{c}\text { Monitors / tracks } \\
\text { diversity }(\%)\end{array}$ & $\begin{array}{l}\text { Sets } \\
\text { progression/ } \\
\text { representation } \\
\text { targets (\%) }\end{array}$ & $\begin{array}{l}\text { Reports } \\
\text { publicly (\%) }\end{array}$ \\
\hline $\begin{array}{l}\text { Race and } \\
\text { ethnicity }\end{array}$ & 79 & 54 & 21 & 21 \\
\hline Gender & 71 & 67 & 75 & 71 \\
\hline Age & 92 & 50 & 4 & 8 \\
\hline Disability & 58 & 25 & 0 & 4 \\
\hline $\begin{array}{l}\text { Sexual } \\
\text { orientation }\end{array}$ & 54 & 21 & 4 & 8 \\
\hline
\end{tabular}

Table 3: Data collection, monitoring, targets and reporting. 
Rafael Campos Valdez is newly appointed as HR Business Partner Diversity and Inclusion at Schroders. He looks after everything related to diversity and inclusion within the company. Schroders' Group Chief Executive, Peter Harrison, took on the role in April 2016 and the diversity agenda is a priority in ensuring that the company is a progressive, inclusive organisation. Rafael states the importance of the work on inclusion and diversity not being labelled an HR-only project. He believes the key to the success of implementing the inclusion and diversity agenda at Schroders is involving the whole business.

Data capture, developing targets Since 2016, Schroders have developed a diversity capture option on their HR database that allows employees to selfdeclare diversity data (ethnicity is one of the options). As data are gathered, Rafael will be able to overlay ethnicity data with talent mapping data. This will provide information of what the management pipeline looks like - from here Rafael will be able to amend the Diversity and Inclusion strategy to reflect the new talent pipeline insight gained. He plans an active campaign to raise the profile of the importance of data capture. However, Rafael emphasises that lack of data should not preclude companies from taking action on diversity and inclusion, and it has not prevented him from moving forward diversity initiatives within Schroders.

"Organisations should stop using lack of data on ethnicity as an excuse to not start taking action... Whilst data is critical for understanding our workforce, tracking progress and running analysis to find trouble areas, it is not critical to shifting the dial on ethnic diversity... We have a Muslim association that has consulted on our new prayer room... These are the kind of things you can do without these figures."

Manager and employee empowerment Each General Management Committee (GMC) member has a diversity and inclusion objective and Rafael works closely with the GMC members to help them challenge the way things are run within their departments. Rafael says that manager buy-in is key to the success of any diversity and inclusion initiative. $\mathrm{He}$ identifies very positive engagement from managers around diversity and inclusion within Schroders. Employee empowerment is also seen as vital at Schroders to lead change. This is led through engagement with employee resource groups. Rafael runs a committee of all employee network chairs and also meets them regularly on a one-to-one basis. Additionally, each network has a GMC sponsor who will meet with them to discuss issues and provide a link for the network to senior levels within the company.

"The only way for real change to occur within a company is by having a pincer approach, support from the very top and from a grass-roots, employee-led angle... This is the approach we have taken at Schroders and I can see changes occurring... A lot of time, organisations create staff networks but don't equip them with the tools, voice or resources to make real change... We're empowering our D\&l leaders to help Schroders become more diverse and inclusive."

\section{Training}

When people become managers in Schroders they are provided with training This includes an element specific to inclusive leadership, covering managing a diverse workforce and being line manager to a diverse team. While specific diversity training is important, Rafael is looking to embed diversity and inclusion education across their suite of management training offers.

"It's more like a sprinkling across all of our offerings, instead of 'go on diversity for one day' and then you don't hear about diversity again for a year... We do have e-learning around diversity in the workplace and discrimination... that's important, but when it comes to engaging employees, [to say] this is what a good manager looks like, it's [diversity and inclusion that is] actually core business, I think changes the conversation more." 


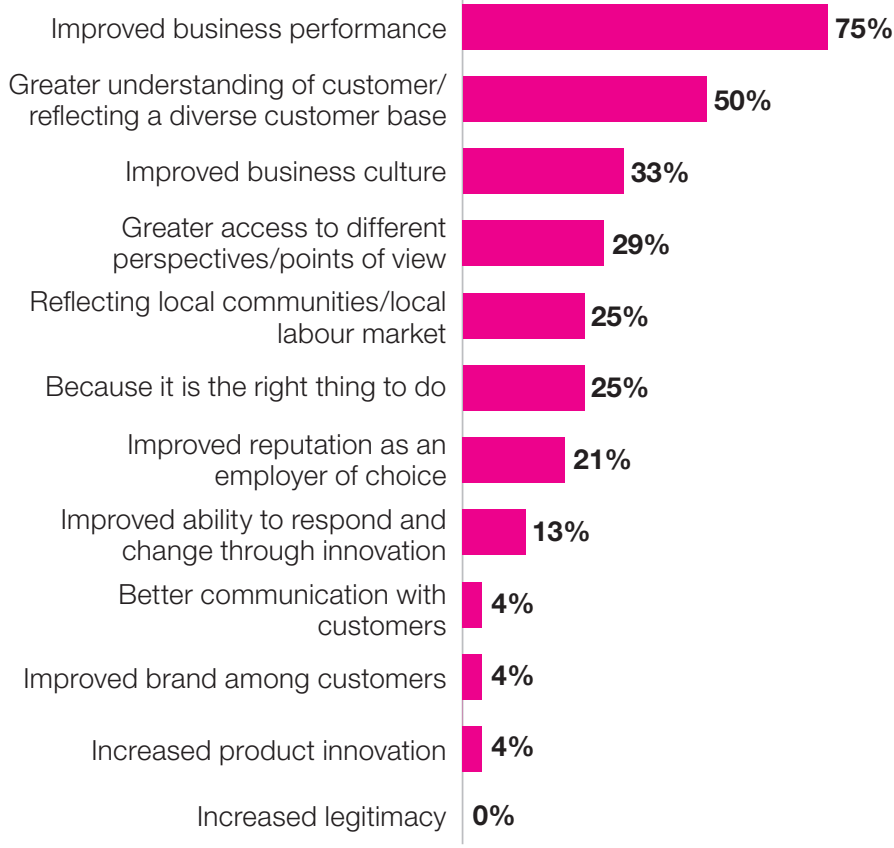

Figure 4: Top five business drivers for improving BAME pipeline.

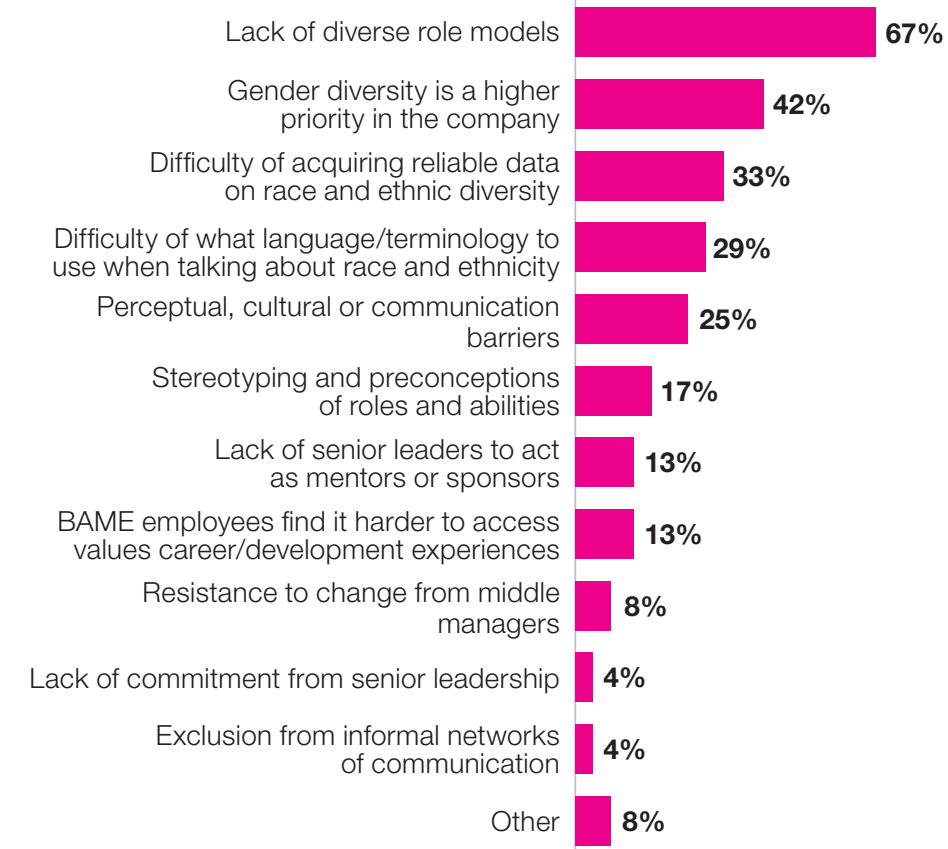

Figure 5: The biggest challenges in promoting race and ethnicity in the pipeline.

\section{Business drivers for BAME diversity There were clear business drivers for taking BAME diversity seriously. Asked to pick the top five drivers, improved business performance was most often cited, supporting the argument that diversity is good for business (see Figure 4). This was followed by improved understanding of a diverse customer base, benefits to the business culture as a whole, and access to different perspectives and points of view.}

Notably, only a quarter reported that action was driven by a social justice imperative, i.e. that 'it is the right thing to do.' This raises the question that if there is no business imperative, then no action to improve inequalities may be likely. ${ }^{34}$ It is clear that senior leaders need to keep making the business case for diversity to tackle inequalities.

\section{The biggest challenges in} promoting race and ethnic diversity in the management pipeline In line with the findings from the qualitative interviews and case studies, a lack of BAME role models was ranked as the top challenge facing companies in promoting race and ethnic diversity, cited by $67 \%$ as shown in Figure 5.
Intriguingly, the priority given to gender was the second most widelycited challenge. While lessons can be learned from the progress made on gender, this suggests that management time and resources have been dedicated to driving change on gender - or even that some businesses may be complacent that their efforts on gender means they have 'done' diversity. (Indeed, BAME people also have a gender and yet, because BAME data is not often connected to gender data, organisations are often unable to say whether BAME men and BAME women fare differently from non-BAME men and women. These issues of intersectionality represent a further level of challenge for companies. In discussion, some recognised the challenge - but often lacked welldeveloped solutions.)

These top challenges were followed by the difficulty of acquiring reliable data, the difficulty of what language/ terminology to use, and perceptual, cultural or communication barriers. 
Aspiring to be the most inclusive retailer, Sainsbury's inclusion strategy crosscuts all diversity dimensions. Each strand of diversity is led by a member of its Operating Board. A Diversity Steering Group, comprising Board Sponsors for each strand as well as senior representatives from across all Sainsbury's Group businesses, meets regularly to govern progress and update the Executive Board and Operating Board.

A dedicated inclusion team is led by Diversity and Inclusion Manager, Hannah Munro. Furthermore, 160 Inclusion Champions across every part of the business support and drive the agenda, delivering key activity.

\section{Senior sponsorship}

Sainsbury's prioritises senior sponsorship in driving inclusion initiatives and achieving success. Sainsbury's Race Reference Group is co-chaired by Group HR Director, Angie Risley, and Director of Transformation, Irvinder Goodhew. Including representation from across the company, this group helps to drive BAME inclusion through focused initiatives and networking activity.

"We have the total buy-in and commitment of our CEO, Mike [Coupe], as well as our senior teams, which has been a huge unlocker for us. Our leaders driving the agenda has helped remove potential barriers and shown colleagues how much we value and embrace diversity in our business."

\section{Developing better insight and understanding}

While $14 \%$ of Sainsbury's colleagues identify as BAME, the retailer strives to do more to ensure the organisation reflects its diverse customers and develops a culture of listening. Feedback is collected regularly through online platforms, focus groups and its Inclusion Champions. For example, this feedback resulted in the development of Sainsbury's 'Little Book of Faith' and 'Little Book of Cultural Awareness', designed to facilitate managers' appreciation of colleagues' diverse religions and cultures. Additionally, specific inclusion questions have been added to the engagement survey.
Sainsbury's co-sponsored the Race at Work survey through Business in the Community. Findings helped shape a series of BAME colleague development events, reaching more than 500 BAME colleagues and Senior Leaders. Hosting these events facilitated conversations about BAME diversity and inclusion, and feedback from these events has been overwhelmingly positive.

Embrace the difference - encouraging a culture of inclusion

During its first ever inclusion week, Sainsbury's launched 'Embrace the Difference', a new inclusion brand. Colleagues were given visible symbols (badges and stickers) to show their support for inclusion and the business ran scenario-based exercises in stores and via office-based meetings, to help equip colleagues to embrace difference. Other activities include a new corporate induction inclusion video and dedicated inclusion sessions as part of 'Bitesize' keynote speaker slots.

Sainsbury's uses Yammer and internal communication channels to share progress and remind colleagues of key events from the diversity calendar. Case studies, articles and videos also inspire and engage colleagues. For example, during Ramadan, the company shared case studies with colleagues, explaining why people fast during this period and answering any questions.

"We want to end the awkwardness and anxiety that colleagues sometimes experience when discussing diversity, encouraging them not to make assumptions but instead to be curious and really get to know each other. In the last 12 months we've seen a significant increase in focus, momentum and attention and more conversations happening right across our organisation."

\section{Mentoring}

Mentoring is key both within Sainsbury's and through partnerships with other organisations. In 2017, each Sainsbury's Operating Board member will host a mentoring circle with BAME colleagues. As champion members of Business in the Community, the company also participates in cross-organisational mentoring opportunities, broadening the reach to other organisations. As founding members of EMpower, Sainsbury's takes part in its mentoring programme, as a result of which they have committed to putting forward colleagues to be both mentors and mentees.

"Mentoring works both ways. It will be really beneficial: through circles [colleagues] will be able to build their networks and raise any development challenges. But equally, it will provide our most senior leaders with some valuable insight, potentially on some of the challenges that BAME colleagues are more likely to face across the organisation. This will ultimately help them to be more inclusive leaders."

\section{Role modelling}

Sainsbury's recognises that lack of senior BAME role models can have a negative impact on progression of BAME colleagues. The company works hard to highlight senior BAME role models, encouraging them to share their stories with as many colleagues as possible. Irvinder Goodhew, Director of Transformation, and Sarah Nelson, Group Financial Controller, were recently recognised for their involvement as role models in the EMpower Top 100 Ethnic Minority Leaders list. Sainsbury's recently launched career mapping tools which depict diverse role models. These role model stories are shared in a variety of ways, through careers events, booklets, the company intranet and Yammer. Hannah describes how role models in a colleague's 'line-of-sight' (i.e. next-levelup) provide a powerful illustration of opportunity for BAME colleagues within the company.

"On an Area Manager's first day, she met with her team... they talked and she really listened. Following the meeting, she received an email from a member of the team. It said: "I just wanted to thank you for today. Until this point I never believed I could progress beyond convenience store manager. I went home and told my husband that my new manager was not only a woman, but she was black! Now I am determined to follow in your footsteps." 


\subsection{Good practice approaches}

HR and D\&I leaders who responded to the survey articulated a number of good practice approaches both as part of the survey questions and also within their additional comments. While we isolate these approaches below, it is worth noting that for them to be effective, they need to work in an integrated way so that the maximum benefit is achieved.

\section{Leadership from the top}

As was evident from the previous section and elsewhere in the report, the role of senior leaders is crucially importance to progressive equality policies. Without the support of a company's leadership, there is little hope for genuine progress on other good practice elements.

\section{Box B: What one change would most improve the career progression of BAME managers in your company?}

\section{"Visible role models"}

"More senior role models - more BAME people at the senior level"

"Increased pipeline of talent coming through the business, supported by a culture of inclusion"

"Increased pipeline of early careers talent to showcase capability and level the playing field"
As one respondent stated: "There does not seem to be a real effort to acknowledge this by non-BAME senior managers who are the biggest influencers of the management progression pipeline."

Senior leadership was one of the most-cited factors in the 'One Change' question, seen as crucial to improving BAME career progression (see Box B).

\section{Outreach}

Outreach recruitment strategies to hire more BAME managers were most common with respect to entry levels and the talent coming into the pipeline, through outreach to schools and colleges (54\%) and outreach to undergraduates/graduates (50\%). Others used their website to demonstrate their commitment to race and ethnic diversity (42\%) and BAME role models in publicity (42\%). Around a third (33\%) set diversity requirements for recruitment agencies/head hunters. $33 \%$ said that they did not have specific strategies for recruiting BAME managers.

Each of these initiatives was rated as effective by $70 \%$ or more of those using the strategies, as shown in Figure 6, suggesting an opportunity to increase their use across business.

\section{Recruitment and selection}

The majority (71\%) believed that an applicant's race/ethnicity had no impact on their chance of success in recruitment (see Figure 7). 71\% also provided diversity training for all interviewers. At the same time, around six in 10 companies (58\%) do not ensure that there is a diversity of race and ethnicity on recruitment panels; and this may be difficult to achieve until there is a higher proportion of BAME representation in companies.

Thus we see a catch 22, where increasing representation is essential for other progressive policies to be effective.

Box C: What one change would most improve the career progression of BAME managers in your company?

"We have seen the biggest impact on the numbers when our senior leadership teams have led from the top and taken ownership for the diversity of their teams. It is only by them challenging and driving their teams to be aware and conscious of bias, and the impact this plays on the people decisions they make, that we can make a lasting difference to the profile of our business"

"Leaders being more comfortable and proactive talking about race and challenging each other on unconscious biases that may be influencing decisions. BAME employees willing to step up and lead the way"

\section{"Diversity champion at board level}

"A senior management sponsored BAME mentoring programme where employee progression data is published to measure programme effectiveness"
Very effective Fairly effective $\square$ Not very effective $\square$ Not at all effective Don't know/not sure
$15 \%$
$69 \%$
$15 \%$

\begin{tabular}{|c|c|c|c|c|}
\hline $17 \%$ & $58 \%$ & & $17 \%$ & $8 \%$ \\
\hline $25 \%$ & $50 \%$ & \multicolumn{2}{|c|}{$13 \%$} & $13 \%$ \\
\hline $10 \%$ & $60 \%$ & $10 \%$ & $10 \%$ & $10 \%$ \\
\hline & $70 \%$ & & & $10 \%$ \\
\hline
\end{tabular}

Figure 6: Effectiveness of outreach strategies to recruit BAME managers.

Base: All those who said they have that specific strategy to recruit BAME managers. 
An applicant's race or ethnic background has no impact on their chance of success

We provide diversity training for all interviewers

We ensure diversity of race and ethnicity on interview panels

It is widely recognised that unconscious bias can undermine applications from BAME applicants. So it was noteworthy that only a quarter of the respondents also reported that they anonymised applications by race/ ethnicity and gender and $29 \%$ by age.

It will be interesting to see if this practice grows bearing in mind that a number of companies mention trialing anonymising applications:

"We have trialled anonymised CVs and are now using the findings to define a future approach."

"We are trialing this for some of our recruitment (early careers including graduates), and are anonymising name, university or school, and qualifications. For our early talent recruitment we undertake name blind recruitment processes."

"[We are] piloting blinding CVs in some countries."

\section{BAME career development strategies}

The most used initiatives and strategies to support BAME managers and their career development were mentoring programmes and BAME employee networks, each used by around half of respondents (see Figure 8). Mentoring and BAME employee networks were widely used in the case studies, for example Lloyds Banking Group (page 24).

As shown in Figure 8, around three in 10 employed leadership development programmes (33\%) and volunteering (29\%).

$29 \%$ reported that they currently have no career development strategies specifically for BAME managers.

\begin{tabular}{|c|c|c|c|}
\hline & $71 \%$ & $13 \%$ & $17 \%$ \\
\hline & $71 \%$ & $4 \%$ & $25 \%$ \\
\hline $29 \%$ & $13 \%$ & $58 \%$ & \\
\hline
\end{tabular}

Figure 7: Recruitment and selection practices.
We also asked those who mentioned a career development strategy to assess how effective they were. The programmes which were reported as $100 \%$ very/fairly effective were:

- mentoring

- leadership development programmes

- sponsorship

- access to placements

BAME employee networks were rated by $73 \%$ as effective, volunteering by $71 \%$, and positive action by $66 \%$.

While these ratings reflect a small base, they are echoed by our case studies and the lived experience interviews. Many organisations would benefit from introducing some of these programmes.
One D\&l lead stated during an interview for our research:

"Rather than just plumping for straightforward mentoring, we decided to go down a reciprocal mentoring group. Because we felt that that would be more beneficial for senior leaders, to understand what it's like to be a minority in a majority culture."
Figure 8: Initiatives and strategies used to support BAME managers' career development.

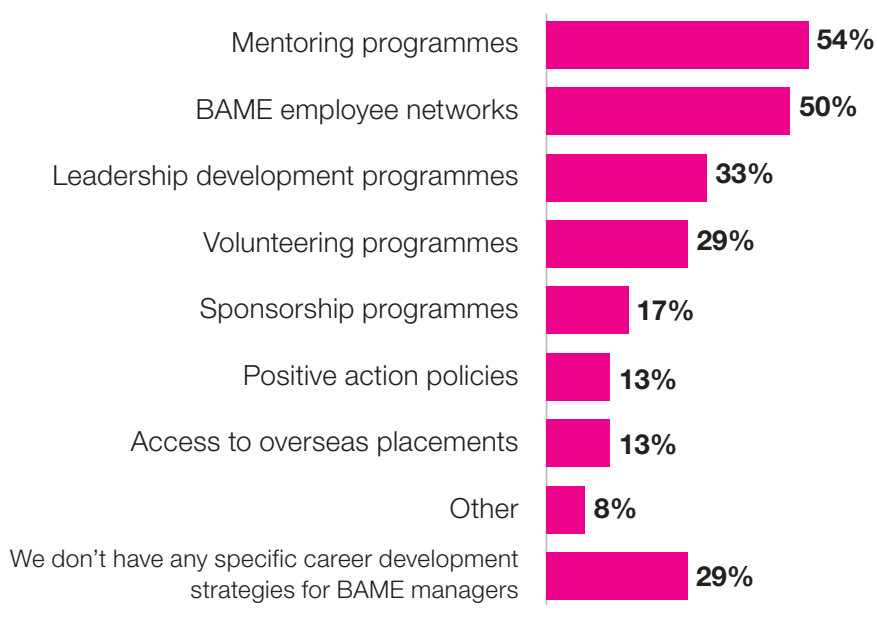

$54 \%$ 


\section{LLOYDS BANKING GROUP}

\begin{abstract}
Lloyds Banking Group employs a team of 10 to work on the inclusion and diversity agenda for all the Bank's c.80,000 employees, reporting directly to the Chief Executive's Office. Sitting separately from HR allows the team to engage directly across the company, convening a monthly group of managing directors from across the business who act as a governance forum. Through this more direct governance arrangement, the team have previously succeeded in mobilising face-to-face inclusion and diversity training for 9,000 line managers within one year, with support from each area of the business.
\end{abstract}

Lloyds Banking Group's stated vision is to Help Britain Prosper, and the company has published targets around inclusion and diversity as part of its strategy. The overall goal is to be more reflective of the customers and communities the organisation serves.

Tracking the BAME leadership pipeline and next-level up role modelling The organisation has tracked and monitored ethnicity data for a number of years and were able to identify that representation of BAME colleagues at a senior management level had plateaued in 2015. This triggered a focus group project which explored the experience of BAME colleagues in the organisation. From this listening exercise, a new strategy on BAME representation was developed, including a number of actions to address a perceived lack of role models. This included the publication of a "role-models list" focusing on next-level-up role models to help BAME colleagues see where they can go within the company.

"What we'd always gone for before was, if we can showcase enough role models at the very senior level then that will encourage colleagues at all levels to aspire to that role. What we didn't fully appreciate was that if you're at an entry level management and your next career step is a middle management role, if you can't see diversity at that level, it doesn't really matter about diversity in the senior management team - it's that immediacy and relatability of role models that's important. We deliberately wanted to have representation at every grade."
To develop this list, the team took nominations in $\mathbf{2 0 1 6}$ for role models throughout the company. From 150 nominations, the team pulled together a list of 40 role models and published the stories of their journeys through the company as a 'magazine' for the business. While it is early to measure impact, BAME colleague engagement levels measured through the annual survey have increased. Lloyds Banking Group has published engagement targets across the company for BAME colleagues, which were exceeded in 2016.

"We have seen a notable increase in engagement for ethnic minorities, our hypothesis would be that the work we have done has driven that. We felt that it was more positive to set some kind of measure of doing something positive rather than saying nothing at all. At least by having an engagement target, we can still hold the business to account for making sure that they are thinking about ethnicity and thinking about cultural awareness."

Networks and communication: REACH Lloyds Banking Group has an established BAME colleague network, REACH (Race, Ethnicity and Cultural Heritage) which has been going for five years. Having executive sponsorship of this network and engagement from senior leaders throughout the company has strengthened the influence of this group. This group hold role-model sessions, and lunch and learn sessions (to which colleagues can dial in by conference call), such as on personal branding, CV writing or career planning. Feedback from these sessions has been positive. Additionally, REACH communicate throughout the company (using their internal communication tool and branch team talk sessions) on a monthly basis including, for example, information about cultural and religious festivals. Recently, REACH have also joined with other networks to run events about joint issues. This includes working with the disability network around mental health.

"We've got a very engaged population of senior executives, who are people managing business units of thousands of people. And they [senior executives] regularly talk about $\mathrm{REACH}$ and the network in their team shouts, or in the blogs they do to their colleagues. REACH

\section{LLOYDS \\ BANKING GROUP}

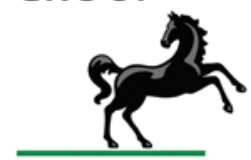

have also had success with running events where colleagues bring their line managers along - that's open to BAME managers or white managers, there's no differentiation."

\section{Recruitment}

An additional area of focus for Lloyds Banking Group has been recruiting from a diverse talent pool. Standardisation of recruitment processes in assessment centres, and unconscious bias training for hiring managers across the company, have been a priority. The Recruitment team have also reviewed the language used in adverts and job descriptions. Advertising has concentrated on attracting diversity in gender, sexual orientation and ethnicity, depicting stories and images that reflect diversity in these dimensions.

"The approach that we would have taken three or four years ago of going very, very corporate, only really sharing positive messages, using lots of stats and lots of facts, is nowhere near as good as telling stories that people can relate to, that people can identify themselves in. So, in our advertising, in our recruitment campaigns and our internal comms, we've very deliberately taken that approach. It's more story-based and a bit more individual. Because it just works better, people engage with it a lot more." 
Agree Neither agree nor disagree Disagree Not answered

Opportunities for promotion are widely advertised

Promotion criteria are clear and transparent

Promotion applications need to be sponsored by line managers

Employees have regular opportunities to reflect on and discuss promotion prospects with line managers

Employees are actively encouraged to self-nominate for promotion

\section{Promotion}

We found evidence of good practice in widely advertising opportunities for promotion, clear and transparent promotion criteria, regular discussions with line managers, and employees' opportunities to self-nominate for promotion (see Figure 9).

Opportunities to self-nominate for promotion are an essential part of the link with sponsorship, mentorship and BAME networks, and should be more widely employed. Otherwise, the motivation gained from other diversity initiatives may be stunted at the promotion gate.

\section{A small number of the leading} companies also adopted positive action strategies. Positive action initiatives to improve the BAME pipeline are activities where a company undertakes to treat BAME employees more favourably, such as providing targeted training and mentoring, where this is a proportionate way to help them overcome disadvantage and under-representation. Note that positive discrimination remains unlawful. However, a 'tie-breaker' allows an employer, faced with making a choice between two or more candidates of equal merit, to take into consideration whether one is from a group that is disproportionately under-represented or otherwise disadvantaged within the workforce.

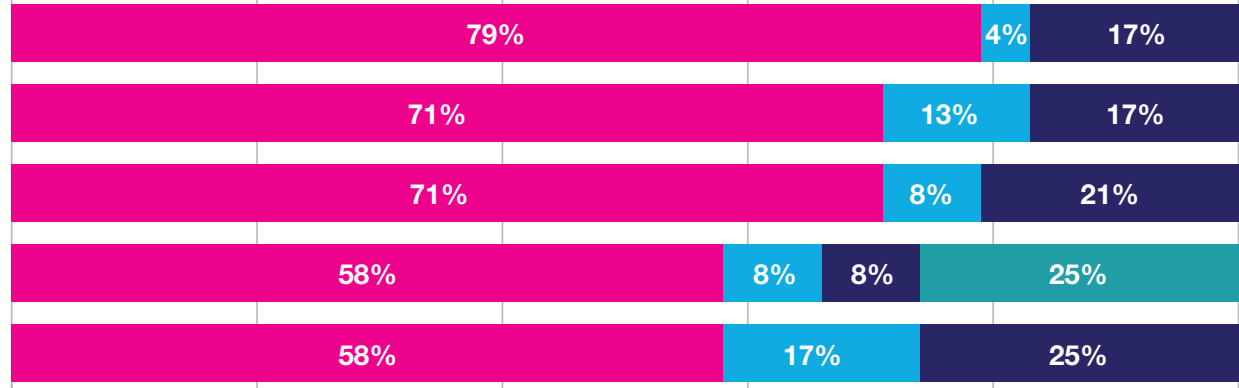

Figure 9: Dimensions of promotion.

Appraisal and performance reviews

Bringing diversity into key staff performance mechanisms, such as appraisal and performance reviews, is recognised as good practice and was evident in the companies that lead the way, both for line managers and senior leaders (see Table 4). Indeed, it is suggested that organisations that establish responsibility see better effects from other initiatives such as diversity training and evaluations, networking, and mentoring. ${ }^{35}$ The effects of establishing responsibility can have wide-ranging impacts on diversity training, networking and mentoring, so should be taken very seriously. Our survey results suggest that this is not the case in practice, with only one organisation reporting that diversity issues were always in appraisal and performance reviews of line managers.

\section{Diversity training}

Diversity training is one of the most common strategies used with respect to diversity as $92 \%$ of respondents said their company provides some sort of training in this area. The most common form was unconscious bias training, reported by $83 \%$, followed by training to combat bullying and harassment (54\%) and cultural awareness training (54\%). What we cannot see from these results is the proportion of the training devoted to specific issues in relation to BAME, as opposed to, say, gender or sexual orientation or disability, or for that matter, the effectiveness of this training.

\begin{tabular}{|l|c|c|c|c|c|}
\multicolumn{1}{l|}{} & Always (\%) & Often (\%) & Sometimes (\%) & Rarely (\%) & Never (\%) \\
\hline Line managers & 4 & 17 & 25 & 38 & 17 \\
\hline Senior leaders & 17 & 8 & 29 & 29 & 17 \\
\hline
\end{tabular}

Table 4: Inclusion of diversity issues in appraisal and performance reviews.
Yet it is decreasingly used at the higher levels of management, where arguably the need for understanding diversity issues is greater, so that the lessons can be cascaded down through the organisation. Of those who provide diversity training, only under half $(46 \%)$ of junior, middle and senior levels of management are provided mandatory diversity training, and only $36 \%$ of Board level.

As made clear in our interviews with D\&l leads:

“We can't expect managers to know absolutely everything. What we can do is share with them some insight as to the value that inclusion brings, in terms of the culture within their teams, and the difference in thought; how it is good for them and how it's good for the wider organisation. And then, help them understand how they can manage diverse teams."

\section{Box D: What one change} would most improve the career progression of BAME managers in your company?

"An in-depth study into the way BAME colleagues experience the workplace and the day-to-day management of their careers, particularly the support (or otherwise) from their managers and senior sponsors. Results to be used to develop awareness and capability training for middle to senior management on how to ensure behaviour around career support is inclusive with regard to different racial and ethnic groups"

${ }^{35}$ Kalev, Dobbin et al. 2006 


\section{Employee voice and representation}

Employee voice and representation are crucial strategies of employee involvement and diversity engagement (see Box D). Views of employees themselves were mostly sought through staff surveys (100\%), HR and diversity teams (92\%), feedback through line managers (83\%), diversity network groups (71\%), and employee relations or other relevant teams within the company (63\%). 58\% sought employee voice through ethics/ compliance hotlines and 46\% through unions.

Given that staff surveys were used by all respondents, it is crucial that analysis by diversity characteristics is undertaken in the survey analysis.

An important area for action is how employee voice is translated into action and the extent to which it accords with the also frequently used management voice i.e. through HR/ diversity teams (92\%), line managers $(83 \%)$, and relevant teams (63\%). It is noteworthy that apart from surveys, employee voice is mostly sought through management channels rather than employee channels; organisations should give some consideration to reviewing this balance.

\subsection{Diversity and inclusion resources}

When asked how many dedicated diversity and inclusion specialists the organisation had, the response ranged from 0 to 10 with an average of 2.8 specialists. Qualitative comments were insightful and indicated some of the concerns as well as good practice that this question elicited. Case study companies indicated the importance of a structured approach to diversity and inclusion, including, for example, a diversity and inclusion team and diversity champions placed organisation-wide (e.g. Sainsbury's case study, page 21). One respondent stated that:

"We don't have any specific people we expect all employees, regardless of level, to encourage diversity and inclusion as a matter of course."
The implicit assumption is that all employees understand the complexity of diversity and inclusion and do not need specialist advice and guidance. In contrast to the above comment, another respondent was more critical:

"One D\&I specialist is a token gesture for a company of its size. How can employees believe that the company is serious about D\&l issues?"

At the other end of the scale, a more progressive company reported that:

"We also have a network of 160 diversity champions across the organisation that help us cascade information, agitate at a local level."

Another more integrated approach through the business was:

"Our Inclusion \& Diversity team has a total of 10 permanent colleagues, supported by regular secondments from the business."

\subsection{Conclusion}

The D\&l leads in 24 FTSE 100 companies who responded to our survey show that those organisations leading the way demonstrated an integrated approach with clear examples of good practice from interrelated actions. These included data collection and monitoring, senior management involvement, positive action programmes, accountability through appraisal and performance review, and staff involvement.

In contrast, there are still companies that are yet to start, have paid little attention to BAME diversity initiatives and were reluctant to invest to improve their diversity and thereby their business performance. We hesitate to speculate about those who did not respond, but given the analysis of the public face of companies (Chapter 7) it is doubtful that many non-respondents are in the 15\% identified as leading the way.
Box E: What one change would most improve the career progression of BAME managers in your company?

"Financial investment in additional resources and headcount"

"One D\&I specialist is a token gesture for a company of its size. How can employees believe that the company is serious about D\&l issues?" 


\begin{abstract}
Marjorie Strachan is responsible for the inclusion agenda across all the RBS brands. She describes their approach to diversity and inclusion as 'matrixed' where her team will look after a specific diversity and inclusion strand, face in to particular business areas and deliver initiatives across the whole bank footprint. Each strand of diversity and inclusion (including the multicultural strand where BAME sits) has an Executive Committee or Board sponsor.
\end{abstract}

Being authentic: An organisation-wide approach to culture change As a transformation specialist, Marjorie states that the focus of the inclusion agenda is culture change across the organisation - led by the CEO Ross McEwan who advocates authentic behaviour and leadership across the bank. Marjorie sees it as something that goes beyond ensuring representative numbers within the organisation to developing understanding of why it is important to have a balance of views around the table at all levels across the business. People are beginning to tell Marjorie and her team that the company "feels different"; in fact, results from the 'inclusion' category in their employee survey are improving year on year and are now the highest in the bank. A particular focus within the BAME inclusion strand is building the leadership pipeline and pulling through more BAME colleagues to senior roles.

"[it's not just about] having more [BAME] people at the top... if they're not engaged and supported, it becomes really tokenistic and artificial. One of the things we try really hard to be is authentic... We're very humble about what we've done so far from an inclusion perspective and a lot of that is because until our employee sentiment balances against...external views of our progress... until those two things match up, we won't truly be an inclusive culture."

\section{Reciprocal mentoring}

Marjorie and the team have set up reciprocal mentoring rather than straightforward mentoring because it was felt that it would be more beneficial for non-BAME colleagues to understand what it was like to be BAME and work in the company. Leaders from across the organisation, including ExCo members, are matched with people from the multicultural network, and reciprocal mentorship is focussed on educating the bank about how RBS can create a better place to work for BAME employees. This mentoring approach also allows BAME employees to be mentored with a focus on moving into more senior roles. As the approach gets embedded, the bank is now seeing relationships cascade to all levels in the organisation as the energy around this initiative takes hold. Marjorie and her team have clearly defined what is meant by mentorship, sponsorship and coaching and are very clear on the level of engagement and the actions required to participate in reciprocal mentoring. Equally as important is the need to monitor and evaluate the success of the programme to ensure it's making a difference. This is being tracked by measuring pipeline growth, promotion rates, disclosure of ethnic orgin levels and employee engagement.

"The idea behind it is that you can't be a champion, unless you have evidence that you are actually doing something... Setting up reciprocal mentoring is helping to educate us around the things that we have to do to make RBS a better place to work for all of our people... It also allows us to get feedback straight away that helps us ensure our plans... to support us pulling through more [BAME] people to more senior roles are the right ones."

\section{Data tracking and information} gathering

Marjorie hopes that these actions will lead to improvement, over time, to disclosure rates amongst employees; currently $20 \%$ of employees are not disclosing their ethnicity in the HR systems. The employee engagement survey at the bank does, however, provide detailed data on the engagement of different ethnic groups. Alongside this, Marjorie and her team have set up a robust system of measurement through quarterly reviews of demographics across the business. Together with monthly contact with employee networks, their sponsors and employee focus groups, Marjorie's team have a multi-layered picture of how they can improve the BAME employee experience and make RBS a great place to work.
"We use that data all the time to make sure that the work packages that we are delivering, the programmes of activity.. are lined up to deliver change against the metrics we set ourselves... We've set up a target around [BAME] pipeline growth... Our focus is further down the pipeline for BAME than it is for gender [senior leadership and pipeline]... We're ambitious and we review it constantly... it's about changing the culture in the bank, it's not a tick-box exercise." 


\section{UNDERSTANDING THE LIVED EXPERIENCE OF BAME MANAGERS}

Diversity and inclusion is not only about policies and practices of businesses. It is fundamentally about the experiences of people working in those companies. We interviewed BAME managers, in junior, middle and senior roles, about their experiences of work.

In this chapter, we outline findings from the 'lived experience' research, which aimed to understand how BAME managers navigate their everyday experiences in their respective companies, and explore their perceptions about how their organisational experiences could be improved.

We conducted a total of 26 interviews, including two pilot interviews, with individuals working in junior, middle and senior management roles (including at director level) across the FTSE 100. These interviews were done among pairs of BAME and non-BAME managers, both working in similar positions in their organisations, which helped us understand the context for their business and identify any differences in experiences.

Analysis of the interviews revealed a number of issues that managers considered important, including:

- perceptions of culture-fit

- senior mentors

- sponsorship

- role modelling
- unconscious bias training - resilience.

BAME managers were generally happy to see a research project that was dedicated to eliciting their views. Both BAME and non-BAME managers bemoaned what they saw as the absence of discussion of race and ethnicity both at a corporate level, and in the way it affects dynamics between people in the business.

Two themes emerged. First, there was a common view that greater transparency would help uncover and address any problems that may exist. Secondly, many BAME and non-BAME managers identified the importance of top management commitment in achieving the cultural and structural changes needed to elevate the issues of race in their companies. These two themes run through the six areas presented below.

\subsection{Perceptions of culture-fit}

BAME managers believed that the perception of individual "fit" was a major driving force that impacted on a variety of organisational experiences, including access to secondments, privileged training programmes, attractive projects and promotion. A high proportion of managers (mostly BAME but also some non-BAME) indicated that there was still a tendency for the "acceptable face" or culture of their company to be defined around values and norms that were 'elitist' and that tended to favour what one manager (non-BAME, female, aged 34) described as "white middle class men from elite schools and universities who tend to recruit people like them." A BAME manager (male, aged 45) attributed the relatively low number of BAME senior managers in his company to the history of this wellknown British organisation. He noted that executives and senior managers at this organisation continued to view their primary role as "maintaining the status quo" and that this has made it difficult to embed the idea of multiple cultures in all organisational activities. As he argued:

"I think the education and the awareness of the people who are in the positions to influence change is not where it needs to be. I think their understanding of the cultural differences, the diversity of the areas in which we operate, society as a whole in terms of the changes in demographics and cultural differences, is lacking... They still groom, mentor and sponsor people who fit the idealised culture."

\section{The comments of a senior manager} (BAME, male, aged 40) at a different company provides further illustration of this:

“There's an immediate assumption when people see me, and that's the kind of thing that gets to me... I think it points to the fact that your name is 
different and as soon as you walk in, your heritage will show and people already have an image in their head... 'he's Asian, so he won't be a fierce leader'."

However, BAME managers were by no means unanimous in their views on the impact of culture-fit. While recognising the potential for perceived lack of culture-fit to hinder individual careers, three BAME respondents (one male and two females) argued that it was the responsibility of the individual to navigate their careers, by seeking ways to understand and work within the cultural requirements of their companies.

One female manager (BAME, aged 30) observed that it was necessary for all employees, especially BAME employees, to acquire cultural knowledge by "learning what matters, who counts and how things are generally done in their organisations." The comments of the other BAME female manager (aged 40), suggested that BAME managers and aspiring managers should work on adapting to any situation they find themselves and should seek ways of overcoming perceived lack of culture-fit. She went on to provide an example of how she works to reduce negative perception:

"When we go to leadership meetings and events, I will always be the only BAME in the room... So I always make an effort to initiate conversations... and sometimes you feel that people are a bit more careful about what they're saying and you notice that their interaction with others like them is a bit more natural... It takes a bit of time but you end up building relationships with them and they become more comfortable next time you meet them."

Such 'covering' practices are deployed to mitigate any perceived and actual differences between BAME and non-BAME members. ${ }^{36}$

\subsection{Senior mentors}

Having a senior mentor in the workplace was seen to be pivotal for career progression (i.e. promotion) for many of our BAME respondents. While some companies have formal mentoring programmes, not all do. Where there are no programmes, the onus is often on employees to approach senior colleagues to ask whether they would be willing to mentor them. In many instances, BAME employees can be quite reticent to approach someone directly.

Along with career development, respondents identified a number of reasons why having a senior mentor is considered to be important. For example, having a sounding-board and networking opportunities, to overcome isolation and feel engaged with and in the organisation, and, perhaps most importantly, to be introduced to (senior) colleagues. Knowledge transfer is also pivotal for a successful mentoring relationship that enhances the skills and knowledge required for BAME employees to become future leaders.

Discussion with employers highlighted the value of next-level and mentoring circles. Mentoring can potentially be beneficial to the company, providing diverse perspectives for the mentor and having better supported employees leads to increased productivity. Indeed, it can create an environment of trust, belonging, support, and engagement for a diverse workforce. It is likely that such attributes would make it easier for BAME employees to raise their concerns and experiences.

In acknowledging the importance of mentoring for career development, a senior manager (BAME, female, aged 31) outlined that her mentor, who was also BAME, was:

"Really, really great at relationship management... having the right balance between having a great coaching conversation versus actually doing the directing as well. [She was] hugely well respected across the organisation. [She was] great at directing me and letting me know how I was getting on with work. If a meeting went really badly or I was feeling down... she would absolutely identify with that [and provide] support." 


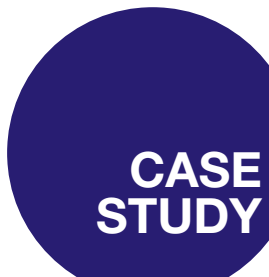

\section{G00GLE}

\section{Google}

\section{Chuck Stephens is Head of Diversity and Inclusion for Google in the Europe, the Middle East and Africa region. He liaises with leaders in the region to promote diversity and create a culture of inclusion. Rather than working with external consultants, Google has created its own centre of excellence that does its own academic research in partnership with universities. Focus for these partnerships is on coming up with leading research and interventions that will help improve employees' working lives, including diversity issues.}

"I don't think people are broken and need fixing, but I think there are things that we can do that would allow them to up their game, to be more successful or bust some myths and correct some of the disconnects on norms within the organisation."

\section{Recruitment and progression} strategies - breaking the silence Most roles in Google require a university degree or qualifications. Chuck and the team are very aware that for the BAME community (in particular the British-Black community), people are more likely to be first generation undergraduates and also more likely to be working while doing their degree, so a longer university trajectory is possible. At the interview stage, Chuck and colleagues have found it useful to navigate these issues and encourage people to talk about more than their academic experiences. For example, asking candidates what they have learned juggling university and working. Additionally, Chuck stresses the importance of engaging with and coaching minority ethnic communities about what they look for in a CV, such as application developer experience.

Chuck identified that as employees, under-represented groups were less likely to self-nominate for promotion - for some, it is counter-cultural to ask for help. By raising awareness of this among managers, and making BAME Googlers aware of trends and norms within the organisation, Chuck explains how it can help improve self-nomination for promotion from BAME groups.
"I mentioned earlier that we found that our British-black peers tended to be very insular in their reach, because asking for help was counter-cultural for some. So talking about the idea that people in our organisation tend to move forward in teams and that it's important to have those critical relationships, actually starts to pull people forward, whenever you are providing transparency to help them be successful."

\section{Activate - a circular mentoring programme}

Activate has recently been launched within the European region based on feedback from focus groups. This is a circular mentoring programme for BAME colleagues, based around the premise that there is a need to facilitate an individual's circle of influence in order to drive their career. Participants are recruited to this programme through internal communications and employee resource groups.

Senior colleagues will mentor a group of around six to seven BAME colleagues.

They will also do peer-to-peer mentoring within that circle. Additionally, participants are offered dedicated courses and the course facilitators, as they get to know these colleagues, become trusted advisors. Furthermore, based on recognition that best mentors are within 18 months of a person's career trajectory, Chuck and colleagues have created a further 'layer' within the mentoring circle between the senior mentor and junior participants. This 'middle-level' mentor provides support to junior participants and also develops a one-to-one mentoring relationship with the senior mentor.

Chuck and colleagues have discovered that most BAME participants on the Activate program believed that it was their manager's role to define and propel their career paths. So the Diversity and Inclusion team have explained to programme participants that it is an individual's own responsibility to drive their careers within Google and that managers are there to help this happen.
“We explained that you've got to decide what it is that you want to be and come up with that vision, then your people manager can help you achieve that. We've had people coming back to us saying that this has transformed the interactions they've had with people managers, because the $B A M E$ Googler is expecting their people manager to do something and that's not happening because the people manager is waiting for the BAME Googler to come to them with their vision. The overwhelming feedback has been transformational in the relationships they are having with each other, and their experience in the organisation. We still have further to go, but are seeing early signs of progress for this program." 


\subsection{Sponsorship}

Many respondents believed that a critical factor in career success was gaining access to a sponsor in their organisation. A sponsor was viewed as someone senior in the company with the necessary power and influence and who has sufficient interest and willingness to act as an advocate and to help increase the protégé's visibility to other executives. The comments of two non-BAME respondents (one male and one female senior managers) help to illustrate the perceived importance of sponsorship in career success:

"When I have been able to make career progression, it has been because l've had someone that l've proved myself to and who has also been willing to sponsor me in terms of pushing my case and making connections with other potential sponsors." (Male, senior manager, aged 38)

"Sponsorship can be valuable. It happened organically for me as I had a boss that I got on very well with. I got to know her well and she obviously saw something in me and gave me the opportunities. I said to my sponsor when she became COO, the job I really want is director of [omitted to maintain anonymity] but it doesn't exist. She said OK, help me out doing something else for the rest of the year and we'll persuade the board in that time... which is exactly what she did." (Female, director, aged 41)

However, while recognising the importance of sponsorship, most BAME respondents believed that the informal ways in which such relationships are developed worked against them. For example, one female senior manager (BAME, aged 47) observed:

"I have seen such relationships work for many others but not for us... My experience has been more about my own individual drive rather than someone helping me."

The suggestion was that companies wishing to advance the careers of BAME employees should appoint a senior director with genuine interest in BAME issues to have overall responsibility for identifying BAME talent and guiding them through the organisation. However, there was little agreement on whether this should be a BAME executive. Some suggested that a BAME director will help to increase authenticity while others noted that the relatively low number of BAME executives suggests that a senior nonBAME executive is more likely to have the strategic leverage to put this at the top of organisational agenda.

\subsection{Role modelling}

Analysis of the interviews revealed widespread agreement on the importance of role models. Role modelling was distinguished from mentoring in that mentoring relationships were viewed as intentional and planned. In contrast, role modelling was seen as spontaneous because it is activated by the mere presence of someone perceived to be a role model. Many respondents (BAME and non-BAME managers) viewed role modelling behaviour as beneficial to companies because it can become an effective way of transmitting desired organisational values and behaviours. As two BAME managers argued:

"We need to find role model behaviour from people who can then create vacuums to suck in others... this is a good practice, it is doable... if I can do it, you can do it too." (Male, senior manager, aged 42)

"We don't have anyone at a real senior leadership level... who's really role modelling [about BAME issues] and saying to BAME colleagues that I am one of you and you can be where I am." (Female, manager, aged 31)

Some BAME respondents were clear that their choice of organisation was heavily influenced by the presence of BAME role models in the target organisations. One BAME director (male, aged 45) recounted the isolation he experienced in his previous organisations where there were no BAME role models. This led him to prioritise this in the choice of his current organisation:

"When I applied for this role and was doing my research, I looked at the board of directors and I noticed that the CFO was BAME... It was important to me to see someone that senior. When I joined, I made the effort to get closer to this guy and he helped me a lot."

Another BAME respondent (male senior manager, aged 48) indicated that the absence of BAME role models had impacted negatively on his organisational experience:

"I entered this organisation with no role models. I still don't have any black and ethnic minority role models above me... I feel that if there was a sort of role model that I could identify with on various things, it would have been helpful to me."

Two BAME managers at different organisations with similarly poor representation of BAME role models suggested that organisations should use executive search agencies to target and recruit BAME leaders with proven leadership qualities that other employees may feel inspired to emulate.

\subsection{Unconscious bias training}

On the whole, most respondents said that they had not experienced (overt) racism in the workplace, although they may have experienced being stereotyped in particular ways because of how they look (i.e. non-White, Asian, ethnic minority). Rather than use the language of racism, some BAME respondents nevertheless did discuss the role of unconscious bias in their company and how training ought to be provided to all employees to overcome this. Unconscious bias was seen to undermine equality in the workplace, to allow double standards to continue, and to hide biases within the organisation.

In discussing the impact of unconscious bias in the workplace, a senior manager (BAME, male, aged 41) said: "When I walk in or somebody sees my name... they have a bias toward who I am, how I think, or what my values are." Some respondents felt that they had missed out on career opportunities (e.g. promotion, fast tracking, leadership roles) not because of racism, but because of unconscious bias. Consequently, BAME employees 
remain invisible and not foregrounded for development in many organisations.

There needs to be continual communication and acknowledgement that bias exists everywhere, so that employers are aware of their inherent biases/prejudices. Unconscious bias training is not a silver bullet, but an important step in the right direction. Some respondents did not agree with the idea of unconscious bias, because it takes away accountability from individuals and organisations.

In discussing why there are so few BAME senior managers in her organisation, one respondent (BAME, female, in her 40s) explained it in terms of unconscious bias:

"There is an element of unconscious bias if you look at the teams, in terms of the management team, and then you start looking at the subsequent teams working down, and you look at their backgrounds you can see that people recruit people that are similar to them, have the same background as them... [There is often] a good representation at the application stage but when it comes to the actual recruitment and offering it doesn't happen because... there is so much bias in terms of people that look like them."

In terms of unconscious bias training, a director (BAME, female, aged 41) remarked that:

"I'm sure none of them is consciously racist, sexist, whatever. But the point is they don't recognise, they don't realise it [i.e. the white, middle-aged, middle class, all male management board]. So I would really like to invest majorly in some work around unconscious bias training."

Another respondent (BAME, male, aged 41) concurred that:

"It's something I think that people should definitely have... It's very interesting [when the results for the training come back] and people see what comes back and they go 'Oh, I didn't think I was like that."'

\subsection{Resilience and "going the extra mile"}

We found that resilience was an important strategy deployed by BAME employees to cope with difficulties in the workplace. Respondents often demonstrated resilience to overcome particular setbacks and for "bouncing back" - e.g. not being promoted, being overlooked, being undermined, having their worthiness underestimated, receiving personal and/ or professional criticism, and managing difficult colleagues.

Many felt they needed to go the "extra mile" (or to do added "emotional housework") for their work and worth to be recognised by senior (nonBAME) colleagues. This entailed respondents reviewing their career trajectories and coming up with clear plans of action. More often than not, some took extra or more junior responsibilities, or a step backwards on the career ladder.

One director (BAME, female, in her 50s) talked about how she often volunteered for challenging projects that most of her (predominantly non-BAME) colleagues avoided so that she could be more visible to senior management:

"For me, the only way to... become visible is actually to pick up projects that are also the most challenging ones... If you want to have an easy life and a cushy [job] you take the little routine job... but if you pick the projects that are challenging for a company, and you know you can make a difference, you typically will be noticed as well... you run through the fire sometimes."

Many other respondents echoed similar sentiments about having to "work harder" than their non-BAME colleagues so that their work and potential are recognised. For the respondent above it proved to be a successful strategy because she was promoted a number of times. Importantly, this is not always the case. Taking on more challenging projects brings an some inherent risk that things will not work out. As another respondent (BAME, male, aged 49) put it, "the goalposts... are always moving" when it comes to BAME-related issues in companies.

\subsection{Conclusion}

These lived experiences and the perceptions of BAME and non-BAME managers highlight the ways in which the careers of BAME employees may be facilitated and supported through directed strategies such as sponsorship, role modelling and unconscious bias training.

The findings also illustrate how BAME employees are navigating culture fit in companies as well and demonstrating resilience. They show that none of these strategies or approaches is a silver bullet in its own right; rather, they have to be mobilised jointly with backing from senior leaders in the company to change the culture. 


\section{THE PUBLIC FACE OF THE FTSE 100}

\section{For the stakeholders of many businesses - not least customers and employees, both current and future - one way of understanding a company's culture is through its online presence. We looked at how far this 'public face' of the FTSE 100 reflects businesses' responsibility to deliver diversity.}

Web presence is vital to the identity and reputation of corporations and it is clear that they all actively manage this vital 'organisational window' for stakeholders. We reviewed images, messages, documents, policies, and other web-based materials of FTSE 100 companies that related to BAME action specifically. The analysis methods were based on previous research into web-based corporate identity evaluation. ${ }^{37}$ We wanted to know: how far are policies, practices and data in key areas of diversity management, and BAME action, represented in the web identity of FTSE 100 companies?

We identified a continuum of the quality of BAME policy representation and action, captured through 'BAME Web Corporate Identity' (BAME WCI). Three main levels were identified.

Leading: there is extensive evidence of good policy and practice, reflected effectively in corporate imagery.

Progressing: there is some evidence of good policy, practice, and some effective corporate imagery.
Starting: or, in some cases, 'Yet to Start'. These companies may have shown an awareness of the need for diversity and BAME action, but limited or no evidence of policy and practice development and limited BAME elements within corporate identity. ${ }^{38}$

An overall pattern emerges of a relatively small group of Leading companies, just over a third of companies Progressing on the journey and about half of companies Starting.

- 15 FTSE 100 companies were found to be Leading

- 35 were Progressing

- 50 are Starting

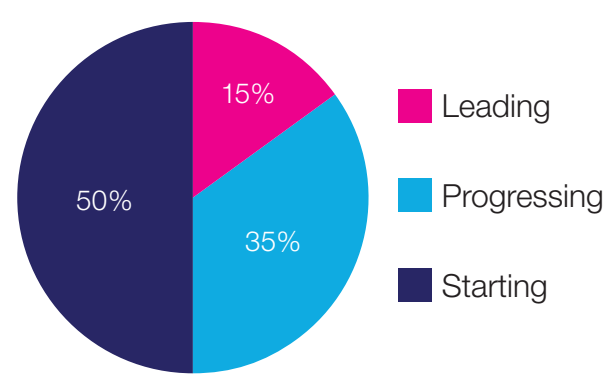

Figure 10: FTSE 100: BAME policy representation and action.

7.1 What does diversity mean? What diversity meant differed from company to company. This suggests the absence of a general agreement about what diversity is in the first place.
Leading: 17 companies seemed engaged with all diversity types, including race/ethnicity.

Progressing: 38 companies included the general diversity types in their narratives but in practice (through initiatives and activities, for instance) they focused on a specific type, typically gender, and less on BAME diversity.

Starting: 45 companies showed no engagement with any specific diversity type in practice, even though such concerns were subtly woven into their narrative.

\subsection{Valuing difference}

Leading: for 13 companies, diversity was not just about the recognition of individual differences, but also valuing individual differences. For instance, these companies focused on discrimination, and also prioritised other related issues, such as work-life balance and flexible working, signifying a recognition of the intersecting and multiple nature of identity and experience of work.

Progressing: for 36 companies, policy initiatives in practice were usually geared towards addressing discrimination and under-representation, particularly on grounds of gender and LGBT, but less so BAME diversity.

Starting: 51 companies were lacking in either of these approaches. 


\begin{abstract}
Aviva's Global Inclusion Director, Jan Gooding, and Head of Diversity and Inclusion, Simon Rodgers, share the ongoing work of their inclusive diversity strategy. As a FTSE 100 company, Aviva operates in 17 markets worldwide, employing around 30,000 people $(16,500$ UK-based), providing 31 million customers with insurance, savings and investment products. Currently, Aviva are going through a transformational shift from a fairly typical large insurance firm to 300-year-old digital disrupter, and with this comes an acknowledged requirement for a diverse workforce. With a third team member joining in May 2017, Jan and Simon emphasise that their inclusion and diversity work is ongoing and cross-cuts all dimensions of diversity (including gender; race and ethnicity; sexualorientation; age; disability; socioeconomic mobility; and health and wellbeing).
\end{abstract}

Building on cultural change Jan and Simon believe that if an inclusive culture is fostered and made integral to strategy then the outcome is diversity. Jan tracks a noticeable change in emphasis in recent years from the idea that a person's difference is "accepted but left at the door" to the notion that diversity is "wanted and difference should be brought in to work". This has led to a groundswell of interest in the inclusion agenda, and an open door for enactment of inclusion strategies to benefit both employees and customers, with the view that greater diversity of people inside Aviva will give the company instinctive empathy with its customers. An example of this was Aviva Pride, the LGBT network, bringing about change to pensions statements, making the language and format much more inclusive of the circumstances of LGBT people.

Jan and Simon hope that this cultural shift, where people feel they truly belong at Aviva, will also lead to a reduction in the reticence of colleagues to disclose their diversity characteristics (in particular BAME and LGBT), something that has been identified in the past.

"What we're now saying is... your difference is really important and we want you to bring your difference to work. I think this is a pretty massive cultural change... We're now saying it's not about fitting in, it's actually not fitting in... it's gone from... 'don't worry we accept you, don't worry be yourself, nothing bad will happen'... [to] 'we'd quite like you to be different because it will help us do better with our customers, and everything we do actively values, respects, and celebrates difference.' So it's nudging it into another phase, which will bring the best people to Aviva where they can do the best work of their lives."

\section{A Global Inclusion Council}

With board-level sponsorship, the team have brought together a Global Inclusion Council. Impetus for this is the recognition that across the different global markets, ethno-cultural diversity cannot be standardised. Chaired by Jan, representatives from around the world have been appointed to the Council by ExCo members. These representatives are seen to be influential within their global market, and therefore can drive the inclusion agenda locally. Jan and Simon emphasise the importance of local ownership of the inclusion strategy. The insights from the Global Inclusion Council will lead to forming a BAME-focused working group in the UK in 2017.

"We don't want ourselves churning out the reports and setting the direction from London that sets the strategy globally. We can set high-level, global strategy but then people own that themselves and drive it within their markets."

\section{The 9-practice plan}

Both Jan and Simons' vast experiences working with Stonewall and Aviva Pride have provided a solid grounding for developing their inclusive diversity strategy. Aligned with the successful Stonewall Workplace Equality Index, Jan and Simon are using a 9-practice approach to the work they plan to do. This is based on best practice for benchmarking inclusion and diversity. The 9-practice plan consists of simple headings covering everything from Suppliers to Data \& Monitoring. These provide focus and navigation for taking forward BAME diversity and inclusion practices across the organisation, alongside the other dimensions of diversity. Jan and Simon emphasise the need to be working on all nine practices simultaneously.
"Nine practices... we have found to be very powerful because you are never doing well in all of those at once, but what you need to say is this is not silver-bullet territory, there are nine things you have to be pushing against all the time. What's important about the model is that the employee resource group is only one of the nine, because I think there is a tendency in old thinking to go, 'let's just have a network' that solves the problem; actually there are eight other dimensions which are embedded in the working practices of the organisation." 


\subsection{Diversity as box ticking or part} of the culture

There is a need to match what companies are doing/have done against what they say.

Leading: 12 companies engaged with the diversity message as "this is who we are."

Progressing: 36 companies engaged with the message as if "this is what we do."

Starting: 52 companies engaged as if it was the vogue, or a style of acknowledging diversity interests/ types to fulfil a "predetermined requirement" or "meet an expectation."

\subsection{Leadership and participation}

There is a need for both specified leadership roles and for diversity action responsibilities to be a recognised part of all line-management roles.

Leading: for 12 companies, leadership for equality and diversity issues came from all levels of the organisation, including line management and nonmanagerial employees.

Progressing: for 36 companies, equality and diversity issues seemed centred on the board and executive committees.

\section{Starting: 52 companies seemed} focused on diversity as the HR department's duties, although there was typically a connection to the board/management committee. They also tried to present themselves as espousing a position as an aspiration, rather than reality or practice.

\subsection{Change programme implementation}

Leading: 13 companies showed diversity programmes and initiatives with results.

Progressing: 34 companies stated these initiatives as being 'in progress.'

Starting: For 53 companies, diversity was an aspiration and a plan with little action evidence produced.

\subsection{Diversity training}

Leading: 11 companies had some form of diversity training programme in place which varied in terms of structure and delivery but showed its link to the business goals of diversity.

Progressing: 37 companies showed some training programmes, but this was not always linked to business goals.

Starting: 52 companies did not show any initiatives relating to diversity training.

\subsection{Employee involvement}

Leading: 17 companies focused on changing cultures and attitudes as a theme of diversity. These companies evidenced a variety of direct forms of employee involvement, including surveys, focus groups, and employee networks, and showed how it was relevant to the management of diversity within the company.

Progressing: 34 companies showed some evidence of employee-led involvement, but lacked practical evidence of functional, integrated, supported and multi-channel forms of employee involvement that could potentially result in significant input by non-management employees. In these companies, diversity management seemed targeted at addressing discrimination and only showed evidence of few practices that introduced or sustained culture change.

Starting: 49 companies showed no evidence of the existence of these groups, and when they did, there was nothing to show functionality or that they had any formal place within the equality and diversity policy and processes.

\subsection{Communicating diversity} Leading: 10 companies reported a wide range of mechanisms for internal communication, including company newsletters and magazines, publicity campaigns, intranet and websites, diversity events and conferences. These included consultations and multi-directional communication.

\section{Progressing: 38 companies} presented some of these materials, typically as instruments for information and dissemination, and so unidirectional, with only a few bidirectional.
Starting: 52 companies did not show use of these channels.

\subsection{Diverse web images}

Leading: 14 companies showed cultural/ racial sensitivity by displaying people of diverse cultures on their websites in an enduring and consistent manner.

Progressing: 33 companies showed some engagement with ethnoculturally diverse images, but only on certain web pages.

Starting: 53 companies showed an absence of this consideration by using only one race (typically white).

However, black people seemed the favoured group to be used to express cultural/racial diversity, sometimes to the neglect of other BAME nationalities/races.

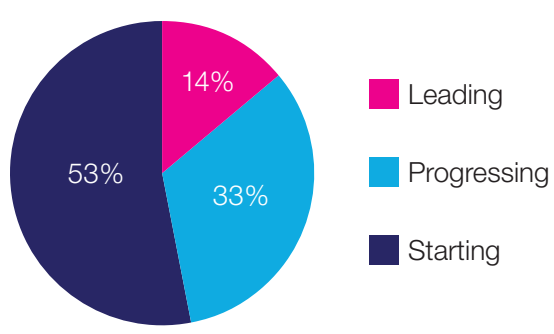

Figure 10: FTSE 100 that use culturally diverse web images

\subsection{Sector differences}

When it came to how companies rated on BAME policies and representation on their BAME web corporate identity, there seemed to be some implications about the company sector they were in. For instance companies in banking, retail and services were more likely to be Leading or Progressing compared to those in construction and mining, which were more likely to be Starting.

\subsection{Conclusion}

Our review of the online public face of the FTSE shows that only a minority of companies clearly show a commitment to deliver BAME diversity.

The message is clear. For most businesses there is a clear need for progress on the journey to greater effectiveness in attracting, retaining and promoting BAME talent - and to ensure that their approach is embedded both in company culture, and in the active presentation of the corporate identity. 


\section{A DEVELOPMENTAL APPROACH TO CHANGING PRACTICE}

The key recommendations for employers on BAME diversity are intended to answer the questions: What should be done? And by whom?

In the following table, we seek to answer the complementary questions:

- How should companies go about developing these practices?

- And how can they assess their progress?

As our research has found, it is unlikely that any company will have perfect performance in all practices. More realistically, companies will be on a progressive journey and will need to make choices about which practices they prioritise.

We provide behavioural indicators in the form of stages of progress to help companies action-plan and self-evaluate their development. ${ }^{39}$ The stages of development are defined as follows.
Yet to start: You may have done some work on other aspects of diversity and inclusion, but so far you have not begun clear and specific action on BAME diversity and inclusion.

Starting: You are aware of the challenges, motivated to make a difference and are starting to make changes.

Progressing: There is increasing buy-in in the company, you are taking co-ordinated action and there are observable changes in practice. You are actively reviewing actions and learning.

\section{Leading the way: BAME diversity} and inclusion are regarded as part of the organisational culture and values and as significant contributors to business success. Your BAME strategy and practices are mainstreamed in management behaviour and others look to you as an example to learn from.
In this chapter, our aim is to provide a pathway to development in companies. The focus is on Progressing and Leading as these are practices that can be aspired to by companies. In our chapters that analyse current practice, such as Chapter Seven on BAME Web Corporate Identity, there is a greater predominance of data in the Yet to Start or Starting categories and smaller proportions in the Progressing and Leading the Way categories.

Opposite, the developmental orientation means that companies can self-evaluate their own practices under each heading and consider how they relate to the Starting/Progressing to Leading the Way continuum. Companies can then decide how to develop.

We have also outlined a specific action of 'one thing to do today' for companies to begin, or self-reflect, on their BAME diversity practices. 


\section{Key

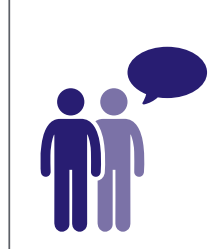

1.

Let's talk about race

\section{Leading}

- An active BAME network is proactively involved in establishing an understanding of issues and giving input to strategy formulation and evaluation

- Indicators and targets are discussed in performance appraisals of managers and leaders including the CEO

- All staff know that it is culturally appropriate to talk about race and ethnicity

- The website and social media communicate exemplars in a prominent and regular way

- Exemplars and personal stories are publicised at corporate, departmental and network levels

- Publicity is given to how BAME staff and leaders have put the exemplars to use to inspire them to take action

- Examples are gathered through appraisal, the BAME network and from individuals on an on-going basis

\section{Starting/progressing}

- Stories of personal experience in the pipeline are gathered proactively, both good and bad

- Learning points are extracted from stories to feed into action plans

- The website is revised to include exemplars in a prominent place

- If there are no internal examples, relevant external examples are used

\section{One thing to do today}

Start your BAME network led by a senior champion. The senior leadership team should give evidence that they are listening to the network by showing how they have changed policy.

HR Director BAME Champion, Management Communications, BAME staff

HR Director

BAME Champion, Management Communications, BAME staff

CEO, BAME

Champion

CEOs and $\mathrm{HR}$

Directors

BAME Network

- Strategies have associated action plans which are publicised and monitored

- There is a shared purpose to improve BAME participation at all management levels

- CVs and applications are BAME 'blind' so that the race and ethnicity of applicants are not revealed to selection decision makers

2.

Learn from the gender agenda
- Selection decision makers are trained and panels include BAME representation

- Staff can self-nominate for promotion and other positions

\section{Starting/progressing}

- Deadlines are set for writing and publishing strategies

- Leaders/Champions with responsibility for BAME diversity are appointed

- BAME staff are involved in strategy formulation

\section{One thing to do today}

Identify the senior leader with responsibility for championing BAME inclusion on the front page of the web site
CEOs and HR

Directors

BAME staff

CEO,

Communications

Director

CEO, HR Directors, Data Managers

Data Managers BAME staff

Mentors

BAME Network $\mathrm{HR}$ action

- Pipeline indicators are identified to give an accurate picture of progression and non-progression

- BAME networks provide a non-managerial forum for collecting experience of progress/non-progress and give anonymised feedback to HR

- Establish exit interviews to understand reasons for leaving. These interviews may be conducted in confidence by non-line management staff or BAME network members

- Communication routes are established for individual information/alerts to be notified to management/ sponsors/HR before BAME staff leave the pipeline

One thing to do today

Provide convincing data protection assurance to BAME staff and clearly explain the need to gather data 


\section{Key

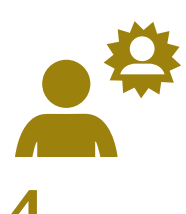

4.

It ain't what you know, it's who knows you.

\section{Leading}

- Senior level sponsors (who may be of any race or ethnicity) are identified to meet BAME staff in the pipeline and help them prepare for their next steps through gaining experience, exposure and enhancing self-presentation

- Sponsors have received clear information on their role

- Sponsors discuss their sponsoring activities in their own performance appraisals

- Sponsors take positive action to help under-represented groups have opportunities and develop their CVs for future promotions

\section{Starting/progressing}

- Sponsors are identified both by the company and by the BAME network

- Training is initiated for sponsors

\section{One thing to do today}

Publicly name the 15 most senior members of the company who will be sponsors.

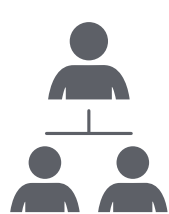

5.

Wanted: role models at every level

\section{Leading}

- Exemplar role models are identified at every level of the management pipeline - the 'next up' role models

- Role models are publicised on the website and are accessible to BAME staff for confidential discussions

- Mentoring is a norm in the culture

- It is a way for the mentee to learn and also, reciprocally, the mentor to learn about BAME lived experience

- The BAME network operates as a place of informal peer-mentoring

- All BAME staff in the pipeline have a mentor

\section{Starting/progressing}

- Role models are identified and short case studies are made available to staff

- Gaps are identified in the pipeline where there are no role models and alternative written examples, sourced from benchmark companies are made accessible to BAME staff

- A mentorship scheme is defined and publicised

- Training is provided for mentors

\section{One thing to do today}

Identify role models and gaps where examples from other companies could be used

\section{Leading}

- Interests and values which exist across multiple cultures are overtly recognised and emphasised in company values

- 'Valuing and learning from difference' is an explicit company value

- Interests and values that differ across multiple cultures are used as opportunities to learn about each other, for example by holding 'share and discuss' sessions around case studies (see the Sainsbury's case study for an example of this about Ramadan)

- The culture is not one of fitting minorities into majority assumptions and patterns of behaviour but everyone having insight into, and mutual regard for, cultural similarities and differences: a culture of adaptive diversity

\section{Starting/progressing}

- The need to move on from minorities fitting in with majority culture is endorsed at senior levels

- Web sites and recruitment material show a diverse set of cultures within the company

\section{One thing to do today}

Senior leaders demonstrate a culture of adaptive diversity by supporting and attending 'share and discuss' sessions on cultural similarities and dissimilarities. FAQs on these sessions are publicised on the website

\section{Leading}

- Benchmarks from sector-specific and internationally leading companies are used to set aspirational targets for BAME management numbers at senior and middle levels

- Performance is measured against benchmarks

- The company is used by others as a benchmark

- Comprehensive diversity training is a requirement for all managers involved in selection decision making at any stage in the pipeline

- Sponsors and mentors have been trained and operate in their own support network

- 'Let's talk about race' is part of all staff induction training

- Completion of diversity training is a requirement for promotion

development: benchmarking externally, and training managers

\section{Starting/progressing}

- Benchmark companies have been identified within and outside the organisation

- Benchmarks are used to define aspired-to outcomes

- Managers and staff are aware of the benchmarks

- A training needs analysis is conducted for managers

- Diversity training, such as unconscious bias training, is implemented for managers making selection decisions

One thing to do today

Select the three most relevant case studies from this report or other reports (see the 'big picture' literature review) and use them to identify top priorities for change
CEO,

Sponsors

CEO,

BAME Network $\mathrm{HR}$

CEO

Role Models

HR Director

Mentors

BAME network

HR Director

Role Models

HR Director

CEO

HR Director

BAME network

CEO

HR Director

CEO

Communications

Director

BAME

champions,

HR Directors

Sponsors

Mentors

BAME

Champions,

HR Directors,

Communications

Managers

BAME Champion, HR Director, BAME network 


\section{FURTHER RESOURCES}

\section{Race}

In the wake of this research, CMI is developing CMI Race, a new network dedicated to supporting BAME diversity at work. CMI Race will work with individual managers and employers to accelerate change. To contribute to the development of the new network or to stay in touch with the latest news, content and event opportunities, sign up via the CMI website.

\section{www.managers.org.uk/ deliveringdiversity}

\section{ManagementDirect - CMI \\ Resources}

ManagementDirect is an online management resource portal that is designed to assist managers overcome everyday challenges as well as support structured learning. Go to the ManagementDirect website for more information.

\section{https://mde.managers.org.uk}

The checklists below focus on diversity and employee engagement within your organisation, and are three of over 200 you can find on ManagementDirect.

- Managing diversity: CMI Checklist 152

- Understanding organisational culture: CMI Checklist 232

- Understanding employee engagement: CMI Checklist 245
Equality and Human Rights Commission (EHRC)

The EHRC is Great Britain's national equality body, and monitors human rights, protecting equality across nine grounds - age, disability, gender, race, religion and belief, pregnancy and maternity, marriage and civil partnership, sexual orientation and gender reassignment.

\section{www.equalityhumanrights.com}

\section{Acas (Advisory, Conciliation and} Arbitration Service)

Acas provides free and impartial information and advice to employers and employees on all aspects of workplace relations and employment law.

\section{www.acas.org.uk}




\section{APPENDIX}

\section{Research methodology}

\section{Case studies \\ Companies that were seen to be undertaking innovative practice in the diversity and inclusion space were identified through a round table discussion in February 2017 and the web-based analysis. Representatives from these companies that had a specific remit for diversity and inclusion were invited to take part in case study interviews. These semi-structured interviews lasted between 50 and 90 minutes (four face to face; three by teleconference) and were undertaken by a member of the academic team and a representative from $\mathrm{CMl}$.}

Participants were asked about: their specific diversity and inclusion remit; the structure of the company in relation to diversity and inclusion; any specific BAME diversity and inclusion projects; any projects related specifically to the BAME management pipeline. The interviews were audio-recorded and transcribed and these transcriptions were used to write up the case studies seen in the report.

These case studies highlight practice in:

- Aviva

- Google

- Lloyds Banking Group

- RBS

- Sainsbury's

- Schroders

- Virgin Money

\section{Lived experience interviews}

The lived experience research explored the experiences of BAME managers through the pipeline. The aim was to give voice to BAME managers and we sought to understand how they navigated their everyday life and work in their respective organisations. We began by conducting two pilot interviews with BAME managers at two large organisations. These interviews, along with the review of literature in this report, helped us to identify the issues that were important in understanding the lived experience of BAME managers.

To generate broader insight into the organisational context as well as the inter-personal/intra-group dynamics in which experiences are developed, we interviewed BAME and non-BAME managers at similar positions in the same organisations. We conducted a total of 26 paired interviews (BAME and non-BAME) in 12 FTSE 100 organisations which agreed to participate in the study. The interviews were open-ended to allow participants to describe their organisational experiences in their own terms. However, we developed a series of broad discussion topics to facilitate the generation of comparable data. These included discussion of the factors that contributed to career choice and satisfaction with current career, discussion of the personal and/or organisational factors that have facilitated or hindered career progress so far, the nature of career support offered by their organisations and whether they think this could be improved, discussion of their experience of being BAME (or non-BAME) in their respective organisations, how they see their careers developing and the individual, organisational and external factors they think are critical to achieving their career objectives.

The interviews lasted between one and one and a half hours, were audio recorded and transcribed verbatim to facilitate the process of analysis. Data analysis followed the recommendations of Strauss and Corbin (1998) and involved a series of coding efforts designed to elicit and integrate emerging themes and patterns.

Quotations from the online survey and interviews have undergone light editing for readability. 
FTSE 100 practices: online survey of HR and D\&I Leaders

The survey was administered during the period 17 March to 8 June 2017 to HR and Diversity and Inclusion leaders in FTSE 100 companies. Participants were assured that their responses would be confidential and that their organisations would not be identified. 24 companies responded, a response rate of $24 \%$ enabling insight into the diversity practices of nearly a quarter of FTSE 100 companies. A response rate of $24 \%$ for a survey is relatively good. However, when we have a small sample, the FTSE 100, this leaves us with 24 responses. The number prevents sophisticated statistical analysis. However, the results are indicative of policies and practices in nearly a quarter of the FTSE 100, which in itself provides a valuable and unique picture of diversity practice with respect to BAME representation and practices.

Responding companies fell into four broad sectors: financial and professional services (FSSP) (10), health and education (H\&E) (2), retail and hospitality (R\&H) (4), utilities (6) and other (9). Companies were also grouped into three broad groups in terms of employee size: those with 5,000 employees or less (5), those with between 5,001 and 20,000 employees (10) and those with 20,001 employees or more (9).

\section{Web corporate identity}

The constructs for the dimensions of BAME were developed by reference to the literature. Several corresponding perceptual measures were then taken for each of these, based on information in the web pages of the FTSE 100 top companies. To validate the constructs, a confirmatory factor analysis (Thompson 2004; Hair et al. 2013) was then undertaken. From this it was shown that weighted aggregates of these measures were able to account for a sufficient amount of the variability present in each of the constructs (Child 2006; Hair et al., 2013). 


\section{REFERENCES AND FURTHER READING}

Anker R. (1997). Theories of occupational segregation by sex: an overview. International Labour Review. Autumn 136:7, 315-340.

BEIS (2017). BME individuals in the labour market: analysis of full representation. https://www.gov.uk/ government/statistics/bme-individualsin-the-labour-market-analysis-of-fullrepresentation

Bradley H. and Healy G. (2008).

Ethnicity and Gender at Work. Palgrave Macmillan.

Healy G., Bradley H., and Forson C. (2011). Intersectional Sensibilities in Analysing Inequality Regimes in Public Sector Organizations. Gender, Work and Organization. 18:5, 467-487.

Business in the Community (BiTC) (2007). Race to the Top: The place of ethnic minority groups within the UK workforce, London: BiTC.

Business in the Community (BiTC) (2011). Race into Higher Education, London: BiTC.

Business in the Community (BiTC) (2012). Race for Opportunity: Leadership and Cultural Identity, London: BiTC.

Business in the Community (BiTC) (2014). Benchmark Survey, London: BiTC.

Business in the Community (BiTC) (2015a). Race at the Top: a review of BAME leadership in the UK, London: BiTC.

Business in the Community (BiTC) (2015b). Race at Work, London: BiTC
Child D. (2006). The Essentials of Factor Analysis (3rd ed.). Continuum International.

Chartered Management Institute (CMI) (2008). Management Recruitment: understanding routes to greater diversity, London: CMI.

Chartered Management Institute (CMI) (2017). Leadership for Change: CMl's Management Manifesto, London: CMI.

Cook A. and Glass C. (2009). Between a rock and a hard place: managing diversity in a shareholder society. Human Resource Management Journal. 19:4, 393-412.

Cornelius, N, Tassabehji, R and Wallace, $\mathrm{J}$ (2007). An analysis of corporate social responsibility, corporate identity and ethics teaching in business schools, Journal of Business Ethics. 76 (1) 117-135

Equal Opportunities Commission (EOC) (2004). Ethnic Minority Men and Women, Briefing, December. Manchester: EOC.

Equal Opportunities Commission (EOC) (2007). Moving on up? The Way Forward, report of the EOC's Investigation into Bangladeshi, Pakastani and Black Carribean Women and Work, March, Manchester: EOC.

Equality and Human Rights Commission (2009). "Financial Services Inquiry: Sex discrimination and gender pay gap report of the Equality and Human Rights Commission." Manchester: Equality and Human Rights Commission.
Equality and Human Rights Commission (2011). "Financial Services Inquiry: follow up report." Manchester: Equality and Human Rights Commission.

Green Park Group (2014). The Green Park Leadership 10 000: a review of diversity amongst the UK's most influential business leaders. London: Green Park Group.

Green Park Group (2015). The Green Park Leadership 10 000: Spring 2015. London: Green Park Group.

Grint K. (2005). Problems, problems, problems: The social construction of 'leadership'. Human relations. 58:11, 1467-1494.

Groysberg B. and Connolly K. (2013). Great leaders who make the mix work. Harvard Business Review. 91:9, 68-76.

Hair JF Jr., Black WC., Babin BJ., and Anderson RE. (2013). Multivariate Data Analysis, 7th Edition. Harlow: Pearson.

Hair J., Sarstedt M., Ringle C., and Gudergen SP. (2017). Advanced Issues in Partial Least Squares Structural Equation Modeling. London: Sage

Harris, LC and Ogbonna E. (2016). 'Ethnic Gatekeeping on the Shopfloor: A Study of Bases, Motives and Approaches', Work, Employment and Society 30:1, 59-76.

Healy, G. and Oikelome F. (2011). Diversity, ethnicity, migration and work: international perspectives. Basingstoke: Palgrave Macmillan. 
Healy G. et al. (2011). "Intersectional Sensibilities in Analysing Inequality Regimes in Public Sector Organizations." Gender, Work \& Organization. 18:5, 467-487.

Home Office (2016). Hate Crime, England and Wales, 2015/16 http:// report-it.org.uk/files/hate-crime-1516hosb1116.pdf

Inclusive Boards (2016). Charities: Inclusive governance. http://www. elevationnetworks.org/wp-content/ uploads/2017/02/Diversity-in-CharitiesReport-November-2016.pdf

Jenkins R. (1988). Discrimination and equal opportunity in employment: ethnicity and "race" in the United Kingdom. In Gallie D [ed] Employment in Britain, Oxford: Blackwell.

Kalev A. et al. (2006). "Best Practices or Best Guesses? Assessing the Efficacy of Corporate Affirmative Action and Diversity Policies." American Sociological Review. 71:4, 589-617.

Kirton G. (2009). Career plans and aspirations of recent black and minority ethnic business graduates. Work, employment and society. 23:1, 12-29.

Kirton G. and Greene A. (2016). The Dynamics of Managing Diversity [4th Edition], Oxon: Routledge

McGregor-Smith Review (2017). Race in the Workplace: the McGregor-Smith Review. London: Luminous.

Metcalf S. and Rolfe H. (2009). "Employment and earnings in the finance sector: a gender analysis." in Research Report. Manchester: Equality and Human Rights Commission.
Ng E. and Spears G. (2010). What women and ethnic minorities want. Work values and labor market confidence: a self-determination perspective. The International Journal of Human Resource Management. 21:5, 676- 698.

Noon M. (1993). "Racial Discrimination In Speculative Application: Evidence From the Uk's Top 100 Firms." Human Resource Management Journal. 3:4, 35-47.

Noon, M. (2007). "The fatal flaws of diversity and the business case for ethnic minorities." Work, employment and society. 21:4, 773-784.

Ogbonna, E. and Harris, LC. (2006). 'The Dynamics of Employee Relationships in an Ethnically Diversified Workforce', Human Relations. 59:3, 379-407.

Oikelome F. and Healy G. (2012). "Gender, Migration and Place of Qualification of Doctors in the UK: Perceptions of Inequality, Morale and Career Aspiration." Journal of Ethnic and Migration Studies. 39:4, 557-577.

Parker Review Committee (2016). A report into the ethnic diversity of UK Boards. London: The Parker Review Committee.

Rogers S. (2011). Non-white British Population Reaches 9.1 million. The Guardian, 19th May

Saggar S., Norrie R., Bannister M., and Goodhart D. (2016). Bittersweet Success? Glass Ceilings for Britain's Ethnic Minorities at the Top of Business and The Professions, London: The Policy Exchange.
Strauss A. and Corbin J. (1998). Basics of qualitative research: Techniques and procedures for developing grounded theory, Thousand Oaks, CA: Sage.

Thompson B. (2004). Exploratory and confirmatory factor analysis: Understanding concepts and applications. Washington DC: American Psychological Association,

Westhuses E. (2004). Workplace Mobbing in Academe, Lewiston NY: Edwin Mellen Press.

Wilson FM. (2014). Organizational Behaviour and Work: A critical introduction [4th Edition]. Oxford: Oxford University Press.

Wallace J. and Cornelius N. (2010). Community development and social regeneration: how the third sector addresses the needs of BME communities in post-industrial cities. Journal of Business Ethics. 97:1, 43-54.

Wood M., Hales J., Purdon S., Sejersen T., and Hayllar O. (2009). A test for racial discrimination in recruitment practice in British cities. Department for Work and Pensions Research, Report No 607. 
CMI is the only chartered professional body for management and leadership, dedicated to improving managers' skills and growing the number of qualified managers.

Our professional management qualifications span GCSE to PhD equivalents, including the unique Chartered Manager award, which increases earning potential and improves workplace performance.

CMI has led the way in developing a suite of trailblazing management apprenticeships with a 40-strong group of employers. These range from Level 3, team leader, through Level 5, operations manager, to the Chartered Manager Degree Apprenticeship. A Master's degreelevel apprenticeship is in development. CMI is a registered apprentice assessment organisation.

We provide employers and individual managers with access to the latest management thinking and with practical online support that helps them to embrace change, create high-performing teams and keep ahead of the curve.

With a member community of more than 140,000 managers and leaders, we promote high standards of ethical practice through our Professional Code of Conduct, and help managers to build their expertise through online networks, regional events and mentoring opportunities.

\section{Visit www.managers.org.uk/deliveringdiversity} for more information, and follow us on Twitter @CMI_managers \#CMIRace
The British Academy of Management (BAM) is a leading learned society representing business and management researchers and academics from over 60 countries. BAM provides leadership in management research, education and supports the field through publication of two prestigious journals, The British Journal of Management and the International Journal of Management Reviews, running a large annual conference, doctoral symposia, more than an event per week and over 20 special interest groups.

BAM works in partnership with key stakeholders including business schools, research funding councils, policy makers, employers, practitioner communities, national and international learned societies to advance and promote business, management and related subject areas.

Visit www.bam.ac.uk/BAMCMI/deliveringdiversity and follow us on Twitter @bam_ac_uk

\section{Report Authors:}

Beech, N., Cornelius, N., Gordon, L., Healy, G., Ogbonna, E., Sanghera, G., Umeh, C., Wallace, J. and Woodman, P.
Copyright Chartered Management Institute @

First published July 2017

All rights reserved. Except for the quotation of short passages for the purposes of criticism and review, no part of this publication may be reproduced, stored in a retrieval system, or transmitted, in any form or by any means, electronic, mechanical, photocopying, recording or otherwise, without prior permission of the publisher.

British Library Cataloguing in Publication Data A CIP catalogue record for this report is available from the British Library ISBN: 0-85946-670-1 